الطباقية الحياتية والتتابعية وتحديد البيئة الترسيبية لتكوين كولوش في منطقة دهوك، شمالي العرلق

$$
\begin{aligned}
& \text { ماجد مجدي عبدالمجيد المتولي } \\
& \text { قسم النفط والتكرير } \\
& \text { كلية هندسة النفط والتعدين } \\
& \text { جامعة الموصل }
\end{aligned}
$$$$
\text { سيف صالح محمد الخليف }
$$$$
\text { تاريخ الاستلام 2020/6/4 تاريخ القبول 2020/8/20 }
$$

$$
\text { جامع علوم الارضة العلية الموصل }
$$

\title{
الملخص
}

يتاول البحث الحالي الطباقية الحياتية والبيئة الترسيبية والطباقية التتابعية لتكوين كولوش في مقطعين ضمن

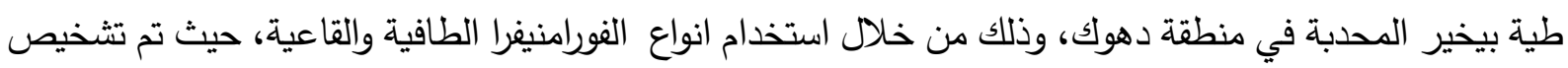
(48) نوعا" تعود الى (14) جنسا من الأنواع الطافية و(34) نوعا تعود الى(19) جنسا من الفورامنيفرا القاعية، وتم

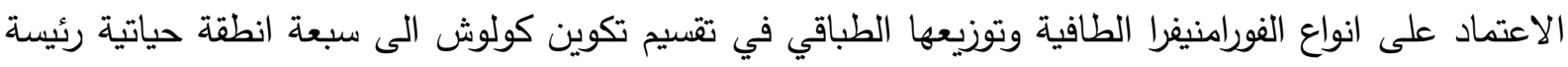

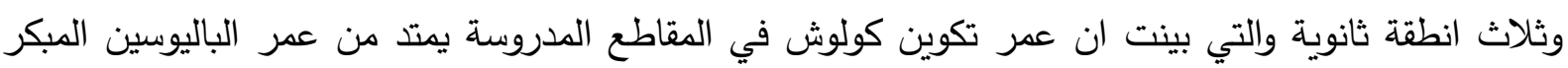
(Danian) خلال الاعتماد على التغاير في تتوع الفورامنيفرا الطافية وكذلك من خلال نسبة الفورامنيفرا الطافية على مجمل حشود الفورامنيفرا، ونسبة الفورامنيفرا الطافية الى الفورامنيفرا القاعية. وتم التوصل الى تحديد البيئة الترسيبية للتكوين

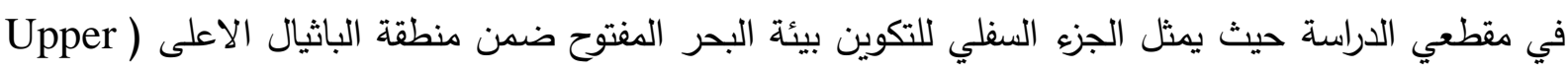

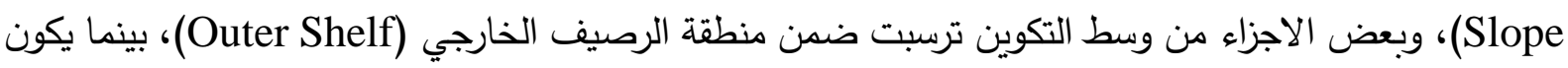
الترسيب ضمن منطقة الرصيف الاوسط (Middle Shelf) في اجزاء التكوين العليا. تمت دراسة الطباقية التتابعية لتكوين كولوش حيث تم تقسيمه الى ثلاث دورات تتابعية من الرتبة الثالثة. ان ان الناه

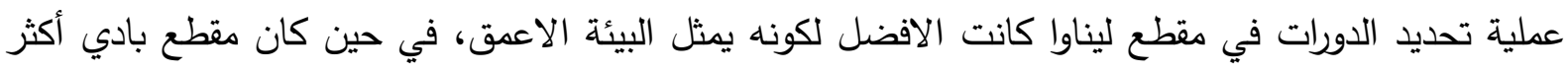

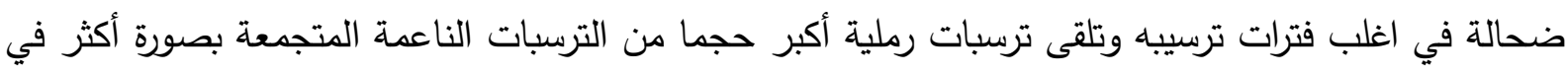

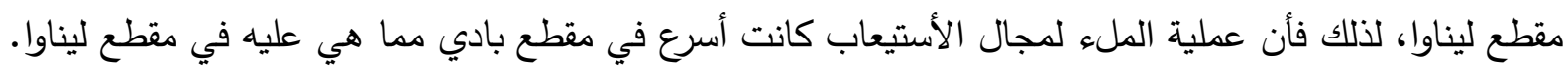

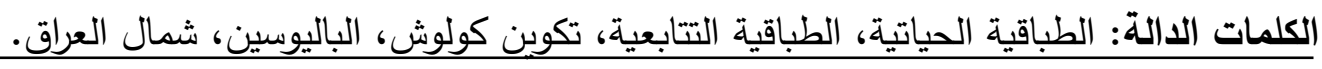

\section{Biostratigraphy and Sequence Stratigraphy and Depositional Environment of Kolosh Formation in Dohuk Area, Northern Iraq}

\author{
Saif Salih Mohammed Al-Khalaif \\ Department of Goelogy \\ College of Science \\ Mosul University
}

\section{Majid Majdi Al- Mutwali}

Dept. of Petroleum and Refining Engineering

College of Petroleum and Mining Engineering Mosul University 


\section{ABSTRACT}

The present study deals with biostratigraphy, depositional environment and sequence stratigraphy of Kolosh Formation in two sections of Bekher anticline, northeastern Iraq by using the planktonic and benthonic foraminifera. Therefore, (48) species of planktonic foraminifera belonging to (14) genera and (34) species of benthonic foraminifera belonging to (19) genera have been recognized. The detailed planktonic foraminiferal investigation permits the recognition of seven well defined biozones and three subzones; they indicate that Kolosh Formation extends from the Early Paleocene (Danian) to Late Paleocene (Thanetian) age. The depositional environment of the formation was studied throughout relying on the variation in the diversity of planktonic forminifera, as well as throughout the ratio of the planktonic foraminifera to the whole mass of foraminifera, and the ratio of planktonic forminifera to the benthonic formiminifera. The lower part of the formation represents the upper bathyal environment, while the middle part deposited within the outer shelf environment, then deposition basin became within the middle shelf area in the upper parts of the formation.

Sequence stratigraphic analysis for the studied sections of Kolosh Formation delineated three sequences which is interpreted as $3^{\text {rd }}$ order sequences, and it is found that the deposition of Kolosh Formation in the Badi section had been occurred in shallower level for most sedimentation intervals compared to the Linwa section which represents a somewhat deeper marine environment.

Keywords: Biostratigraphy, Sequence stratigraphy, Kolosh Formation, Paleocene, Northern Iraq.

\section{المقدمة}

يعتبر تكوين كولوش من التكاوين المثالية في العراق لدراسة انواع الفورامنيفرا الطافية والقاعية، واهم مايميزه

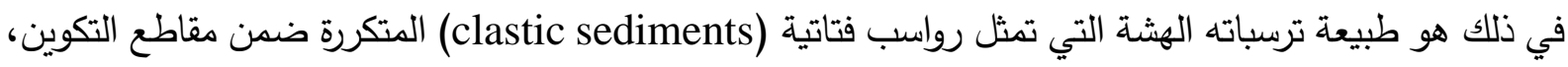

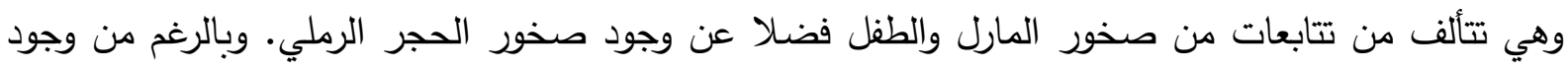

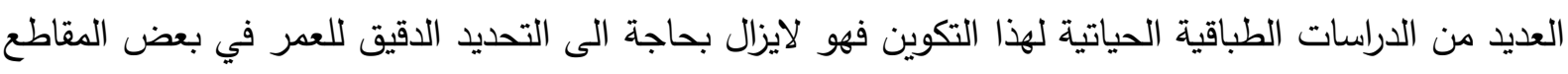
غير الدروسة سابقا، اضافة الى الحاجة لدراسة البيئة الترسيبية القديمة والطباقية التتابعية ( sequence (stratigraphy لترسبات هذا التكوين.

\section{الموقع الجغرافي لمنطقة الدراسة}

تثمل الدراسة الحالية تتابعات الباليوجين الاسفل المتمثلة بتكوين كولوش ضمن مناطق الطيات العالية (شكل

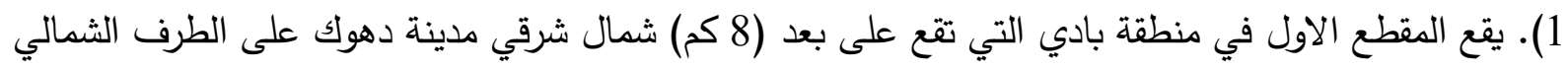

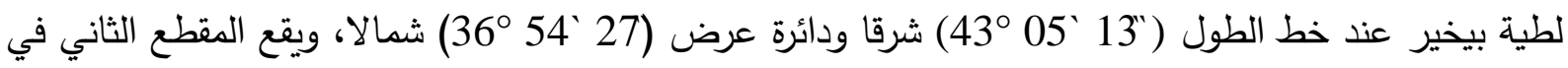

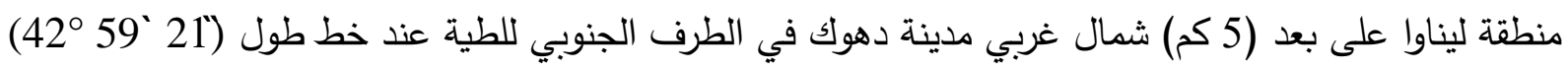

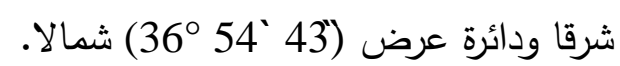




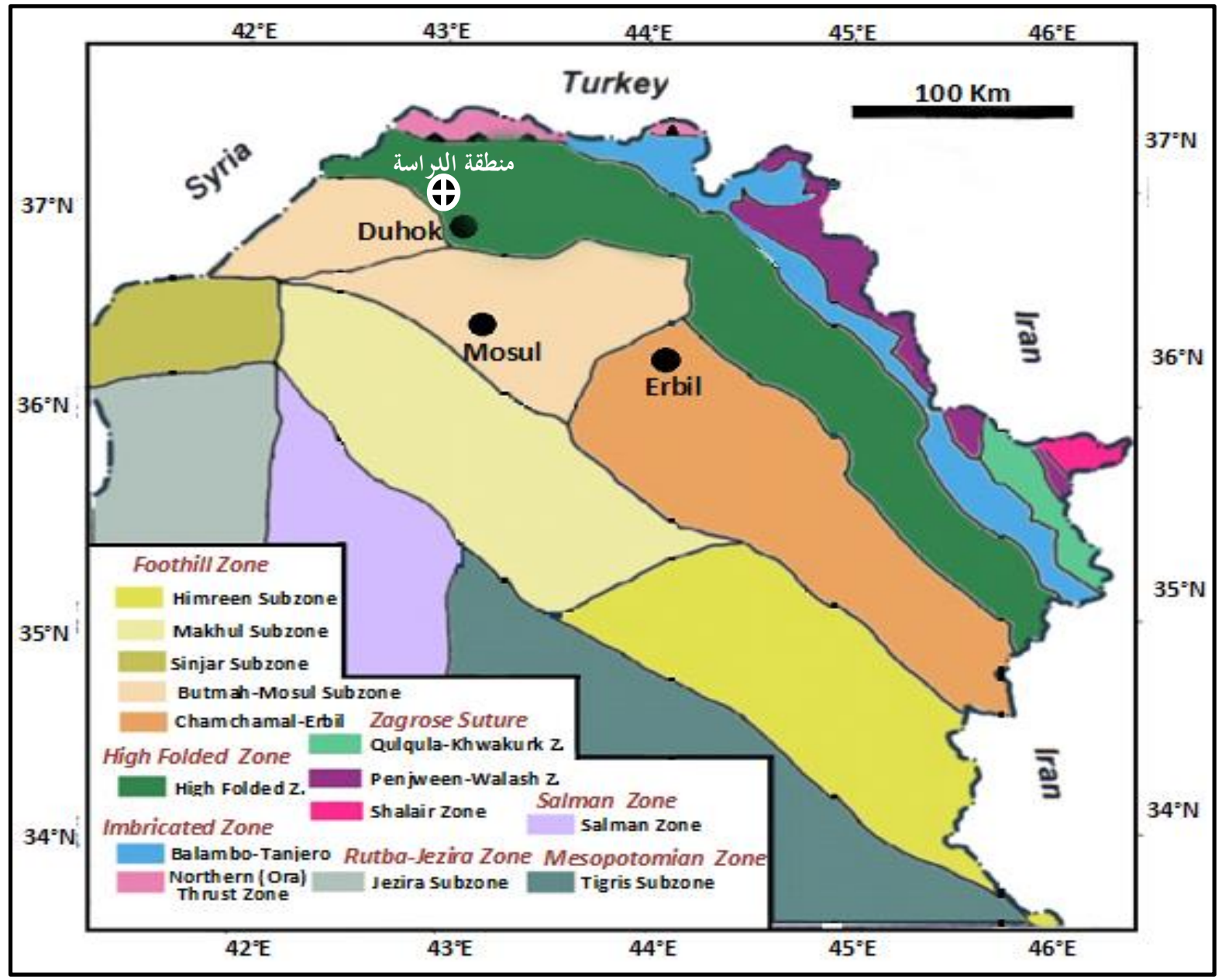

الثكل 1: خارطة التقسيمات التكتونية شمال شرق العراق موضحاً عليها منطقة الدراسة، عن ) Jassim and Buday, .). (2006

\section{أهداف البحث}

تتركز اهداف البحث الحالي على دراسة الطباقية الحياتية والبيئة الترسيبية لمكاشف هذا التكوين ضمن المقاطع المقترحة للدراسة وتحديد طبيعة واعماق الحوض الترسيبي خلال هذه الفترة من خلال طبيعة انواع واجناس حثود الفورامنيفرا القاعية ونسب الفورامنيفرا الطافية الى القاعية. كما تشمل الدراسة الحالية التقسيم الطباقي التتابعي لمقاطع تكوين كولوش على ضوء النتائج المستحصلة من الدراسة الطباقية الصخرية والحياتية والزمنية ومحاولة ربط نتائجها بين مقطعي الدراسة.

\section{الوصف الصخري وحدود التماس لمقاطع الدراسة}

تظهر التتابعات الرسوبية لتكوين كولوش في مقطعي الدراسة الحالية المتمثلة بمقطع بادي في الطرف الثمالي لطية بيخير ومقطع ليناوا في الطرف الجنوبي للطية اختلافا بسيطا في التركيب الصخري وطبيعة الترسبات. بالنسبة لمقطع (بادي) يبلغ سمك تكوين كولوش فيه ما يقارب (280) مترا وتم اخذ (35) نموذجا منه، وتسود في هذا المقطع صخور الحجر الرملي بثكل كبير على امتداد مقطع التكوين حيث توجد من بدايته بشكل متقطع وتستمر الى نهاية المقطع فضلا عن صخور الطفل الاسود والقليل من صخور المارل والحجر الجيري الرملي والسلت. اما بالنسبة لمقطع (ليناوا) فيبلغ سكك تكوين كولوش فيه مايقارب (285) مترا وتم اخذ (52) نموذجا منه 
ويتكون الجزء السفلي منه من تعاقبات من صخور المارل ذات اللون الرصاصي الغامق، أما الجزء الاوسط فيتكون من تعاقبات من الطفل والحجر الرملي والحجر الجيري الرملي، والجزء العلوي يتكون من صخور الحجر الرملي. اما بالنسبة لحدود التماس للتكوين بالنسبة لمقطع بادي فقد لوحظت بعض الدلائل الحقلية بين تكوين كولوش وتكوين شرانش، حيث ينتهي تكوين شرانش بتتابعات من المارل الرصاصي الفاتح وتعلوه طبقة طينية ذات سمك (50) سم تعقبها طبقة من الحجر الجيري بسمك (60) سم تمثل بداية تكوين كولوش. اما مقطع ليناوا فلم يلاحظ وجود اي دلائل حقلية على حالة عدم التوافق الموجودة بين التكوينين، حيث لم يسجل وجود اي طبقة من المدملكات او معدن الكلوكونايت او سطح من الارض الصلبة، وانما لوحظ استمرار الترسيب عند الانتقال ضمن الطبقات الصخرية من اعلى تكوين شرانش الى اسفل تكوين كولوش والمكونة بشكل عام من صخور المارل مع ملاحظة التغاير في حشود الفورامنيفرا الطافية بين التكوينين، بينما يحد تكوين كولوش من الاعلى تكوين خورمالة الذي يظهر في منطقة الدراسة بشكل عدسات وذلك في الجزء الاعلى لتكوين كولوش. ويظهر هناك تغاير حقلي واضح في التركيب الصخري من صخور الحجر الرملي الخضراء العائدة لتكوين كولوش الى صخور الحجر الجيري الصلبة ذات اللون الاصفر البيجي والتي تبرز بشكل حرف واضح في الحقل نتيجة لصلابتها ومقاومتها للتعرية، ويبدو الحد الفاصل بين تكوين كولوش وتكوين خورمالة متدرجا في الحقل ومتوافقا طباقيا حيث يحدد بأول تسجيل لصخور الحجر الجيري ذات اللون البني الفاتح العائدة لتكوين خورمالة.

\section{الاراسات السابقة}

تتاولت دراسة (Lawa, 2004) تحليل الطباقية التتابعية لفترة الباليوسين الاوسط- الايوسين الاوسط في السليمانية الجزء الاوسط والعلوي من تكوين كولوش. وكذلك حددت دراسة (الوزان، 2007) تكوين كولوش في الإنيان منطقة دهوك شمال العراق وجود (47) نوعا تعود الى (14) جنسا من الفورامنيفرا الطافية، واعتمادا على التوزيع الطباقي لهذه الانواع من الفورامنيفرا الطافية تم تقسيم تكوين كولوش الى خمسة انطقة حياتية. حدد (البقال، 2013) في الحد السفلي لتكوين كولوش في منطقتي دهوك وشقلاوة شمال شرقي العراق (16) نوعا تعود الى (8) اجناس، وحدد من خلالها ثلاثة انطقة حياتية للباليوسين الاسفل هي (P0 , Po , P1) وثلاثة انطقة حياتية ثانوية ضمن النطاق الحياتي P1 وهي ( P1a , P1b , P1c).

\section{الطباقية الحياتية لتكوين كولوش BIOSTRATIGRAPHY}

تم الاعتماد في هذه الدراسة على نظام التقسيمات الموضوع من قبل ( Olsson et al., 2000 ). حيث تم تحديد سبعة انطقة حياتية رئيسة هي (P0, Pa, P1,P2,P3,P4.P5) من الاقدم الى الاحدث، وثلاثة انطقة ثانوية هي (P1a ,P1b \& P1c) تابعة لعمر الدانيان استنادا الى التوزيع الطباقي للفورامنيفرا الطافية. وقد تم الاعتماد على العمر المطلق للحدود العلوية والسفلية لهذه الانطقة الحياتية استنادا الى مقياس الزمن الجيولوجي الموضوع من قبل ( Olsson et al., 2000$)$ وتم عمل مضاهاة لهذه الانطقة محليا مع الانطقة الحياتية المكافئة لها والمحددة ضمن الدراسات السابقة التي جرت في مناطق متفرقة من العراق، كما وتمت مضاهاة هذه الانطقة مع الانطقة الحياتية المكافئة في مناطق مختلفة من العالم، وهي كما يأتي من الاقدم الى الاحدث: 


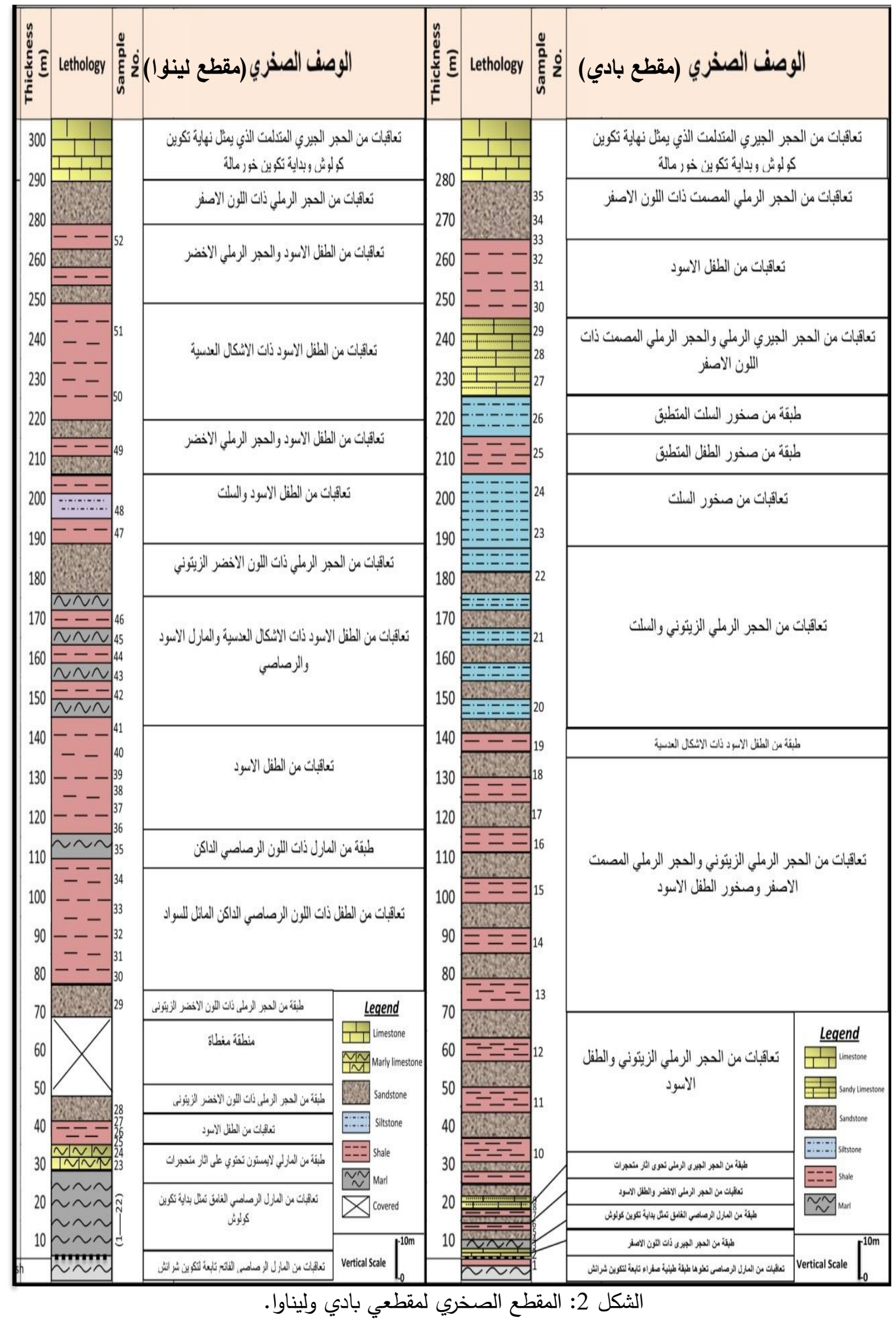




\section{1 -Guembelitria cretacea Partial Range Zone (P0)}

هو نطاق مدى طباقي جزئي للنوع (Guemblitria cretacea) المحصور بين اخر ظهور لكتحجرات

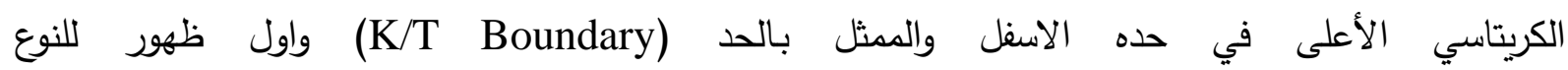
(Parvularogoglobegirina. Eugubina) اما مقطع بادي فلم يتم تثخيص هذا النطاق، وتم تحديد العمر لهذا النطاق بالباليوسين الأسفل المبكر (الدانيان).

\section{2-Parvularugoglobigerina eugubina Total Range Zone (Po)}

يتمثل هذا النطاق بالددى الطباقي الكلي للنوع المسىى به النطاق، وحدد هذا النطاق لاول مرة من قبل

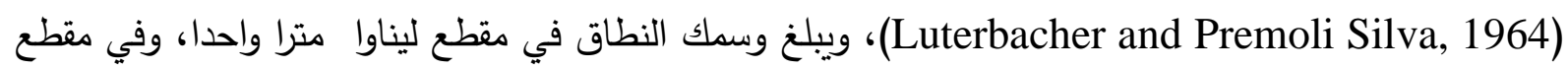
بادي) متران. وتم تحديد العمر لهذا النطاق بالباليوسين الأسفل المبكر (الدانيان).

\section{3-Parasubbotina pseudobulloides Partial Rang Zone(P1)}

هو نطاق مدى جزئي ممثل بجزء من المدى الطباقي الحياتي للنوع Parasubbotina pseudobulloides (Plummer) (15.5) مترا وفي مقطع بادي بسك (25) مترا، وتم تقسيم هذا النطاق الى ثلاثة انطقة حياتية ثانوية وهي: a-Parvularugoglobigerina eugubina -Subbotina triloculinoides Interval Subzone (P1a) b-Subbotina triloculinoides- Globanomalina compressa Interval Subzone (P1b) c-Globanomalina compressal Praemurica uncinata Interval Subzone (P1c)

$$
\text { وتم تحديد العر لهذا النطاق بالباليوسين الأسفل المبكر (الدانيان). }
$$

\section{4-Praemurica uncinata Interval Zone (P2)}

هو نطاق مدى فاصـل يتم تحديده بين اول ظهور للنوع الدال وال Praemurica uncinata (Bolli) وأول ظهور للنوع الدال Morozovella angulata (White) وتم تثـخيصـه من قبل ( Berggern et al., 1995 (B) ويبلغ سمك هذا النطاق في مقطع ليناوا (55) مترا، وفي مقطع بادي ييلغ سمكه (70) مترا_وتم تحديد العمر لهذا

\section{5-Morozovella angulata Interval Zone (P3)} النطاق بأواخر الباليوسين الدبكر. يمثل نطاق مدى فاصل يتحدد بين اول ظهور للمتحجر الدال Morozovella angulata (White) وأول ظهور للمتحجر الدال Globanomalina pseudominardii (Bolli) ويبلغ سكك هذا النطاق في مقطع ليناوا بحدود (60) مترا، اما مقطع بادي فلم يتم تحديد سمك هذا النطاق بشكل دقيق وذلك لوجود شحة في المتحجرات وكذلك الظهور المتقطع لها، وكذلك الحال بالنسبة للانطقة التي تعلوه، وتم تحديد العمر لهذا النطاق بالباليوسين المتوسط (Selandian).

\section{6-Globanomalina pseudomenardii Total Range Zone (P4)}

يمثل نطاق مدى كلي يتحدد بأول بظهور للمتحجر الدال Globanomalina pseudomenardii (Bolli) وتم تعريفه لأول مرة من قبل (Berggern et al., 1995)، ويبلغ سمك هذا النطاق في مقطع ليناوا

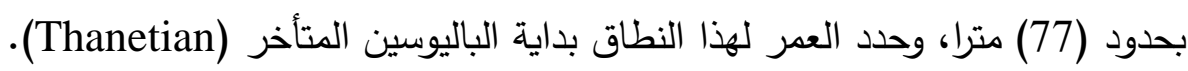




\section{7-Morozovella Velascoensis Partial Range Zone (P5)}

يمثل نطاق مدى حياتي جزئي للنوع الدال Morozovella Velascoensis (Cushman)، ويمثل هذا النطاق ما تبقى من تكوين كولوش الى حدود التماس مع تكوين خورمالة ويبلغ سمك هذا النطاق في مقطع ليناوا بحدود (62) مترا، وحدد العمر لهذا النطاق بالباليوسين المتأخر (Thanetian).

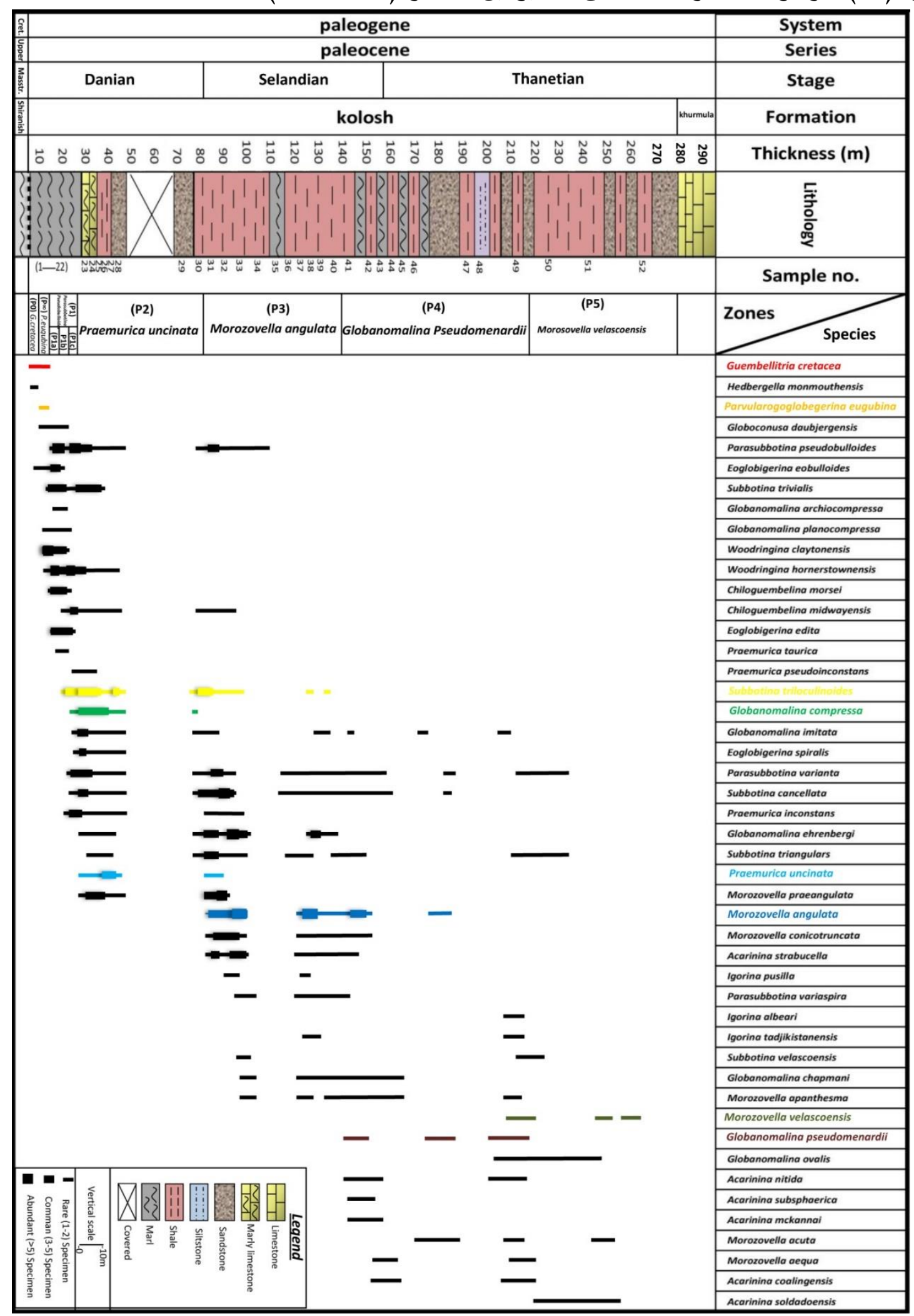

الثكل 3: المدى الجيولوجي والانطقة الحياتية للفورامنيفرا الطافية ضمن تكوين كولوش (مقطع ليناوا). 


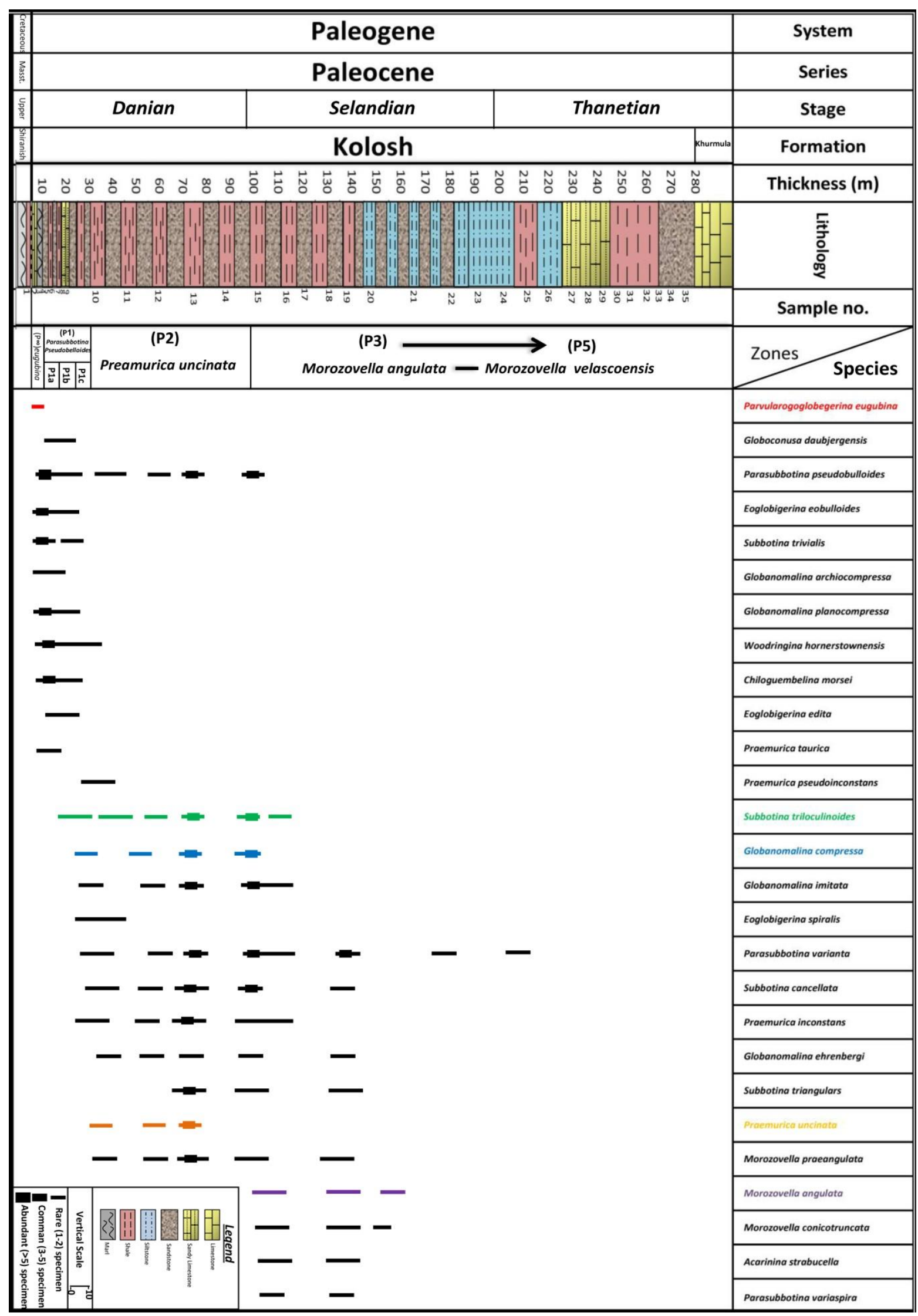

الشكل 4: المدى الجيولوجي والانطقة الحياتية للفورامنيفرا الطافية ضمن تكوين كولوش (مقطع بادي). 
الطباقية الحياتية والتتابعية وتحديد البيئة الترسيبية لتكوين كولوش في منطقة دهوك، شمالي العراق

\begin{tabular}{|c|c|c|c|c|c|c|c|c|c|}
\hline & & & & & & ogene & & & System \\
\hline & & & & & & ocene & & & Series \\
\hline & & & & & & Sel & & tian & Stage \\
\hline ํㅜㅇ & & $\begin{array}{c}\text { (P1) } \\
\text { pse }\end{array}$ & $\begin{array}{l}\text { asut } \\
\text { obel }\end{array}$ & & & & & & $\tilde{0}$ \\
\hline 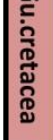 & 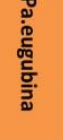 & 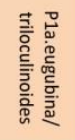 & 总 & 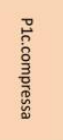 & 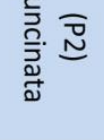 & 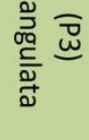 & 氮 & 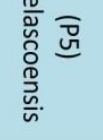 & 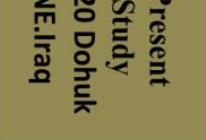 \\
\hline & & Grt.p. & idob & jides & & & & $z$ & $\bar{\sigma}_{0} \vec{o}_{\infty}$ \\
\hline & 势 & 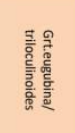 & 号 & 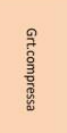 & & & 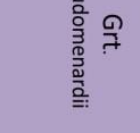 & 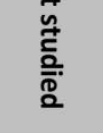 & 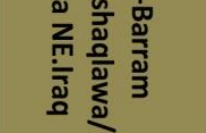 \\
\hline & & Grt. & nida & nsis & & ด & & \% & \\
\hline & 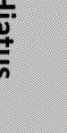 & 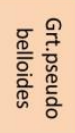 & 产 & 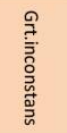 & 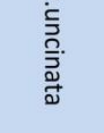 & 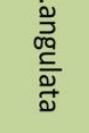 & 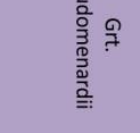 & 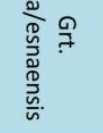 & 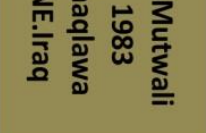 \\
\hline & & 胥 & & & 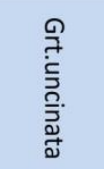 & 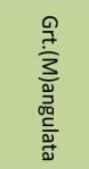 & 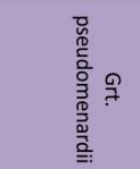 & 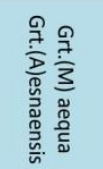 & 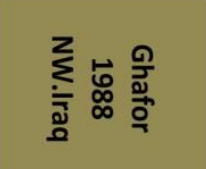 \\
\hline & 灓 & & & & 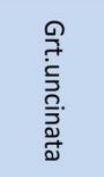 & 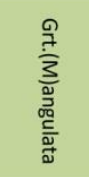 & 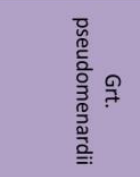 & 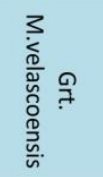 & 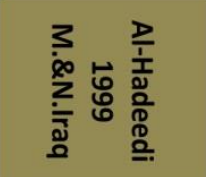 \\
\hline & & z & & & 9 & 9 & M.Velasco & Iadoensis & $\stackrel{D}{D}>$ \\
\hline & & 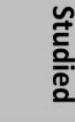 & & & 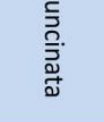 & 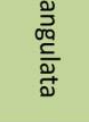 & 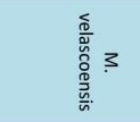 & 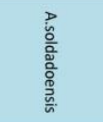 & 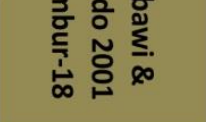 \\
\hline & & & 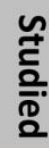 & & & 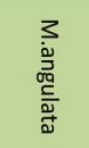 & 8 & 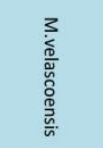 & 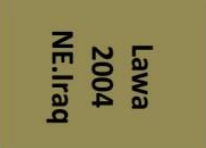 \\
\hline & & & & suides & ס & 3 & : & $z_{i}$ & \\
\hline & $\begin{array}{l}\overline{\bar{\sigma}} \\
\stackrel{\overrightarrow{\tilde{c}}}{\tilde{\omega}}\end{array}$ & & & 起 & 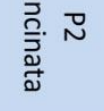 & 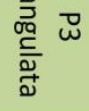 & 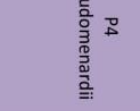 & 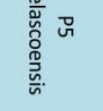 & 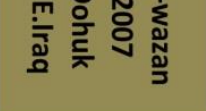 \\
\hline 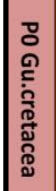 & 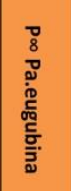 & 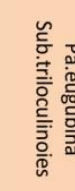 & & 总 & & & & & 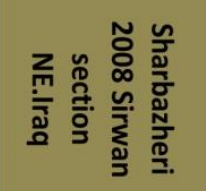 \\
\hline ○ & 8 & $\begin{array}{c}\text { (P1) } \\
\text { pse }\end{array}$ & obell & & & & & & \\
\hline 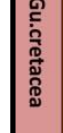 & 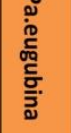 & 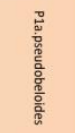 & 言 & 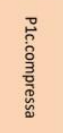 & & & & & 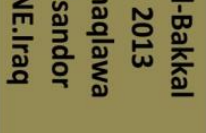 \\
\hline
\end{tabular}

الثكل 5: مضاهاة الانطقة الحياتية للفورامنيفرا الطافية ضمن تكوين كولوش في الدراسة الحالية مع عدد من الدراسات في العراق. 
سيف صالح محمد الخليف ماجد مجدي عبدالمجيد المتولي

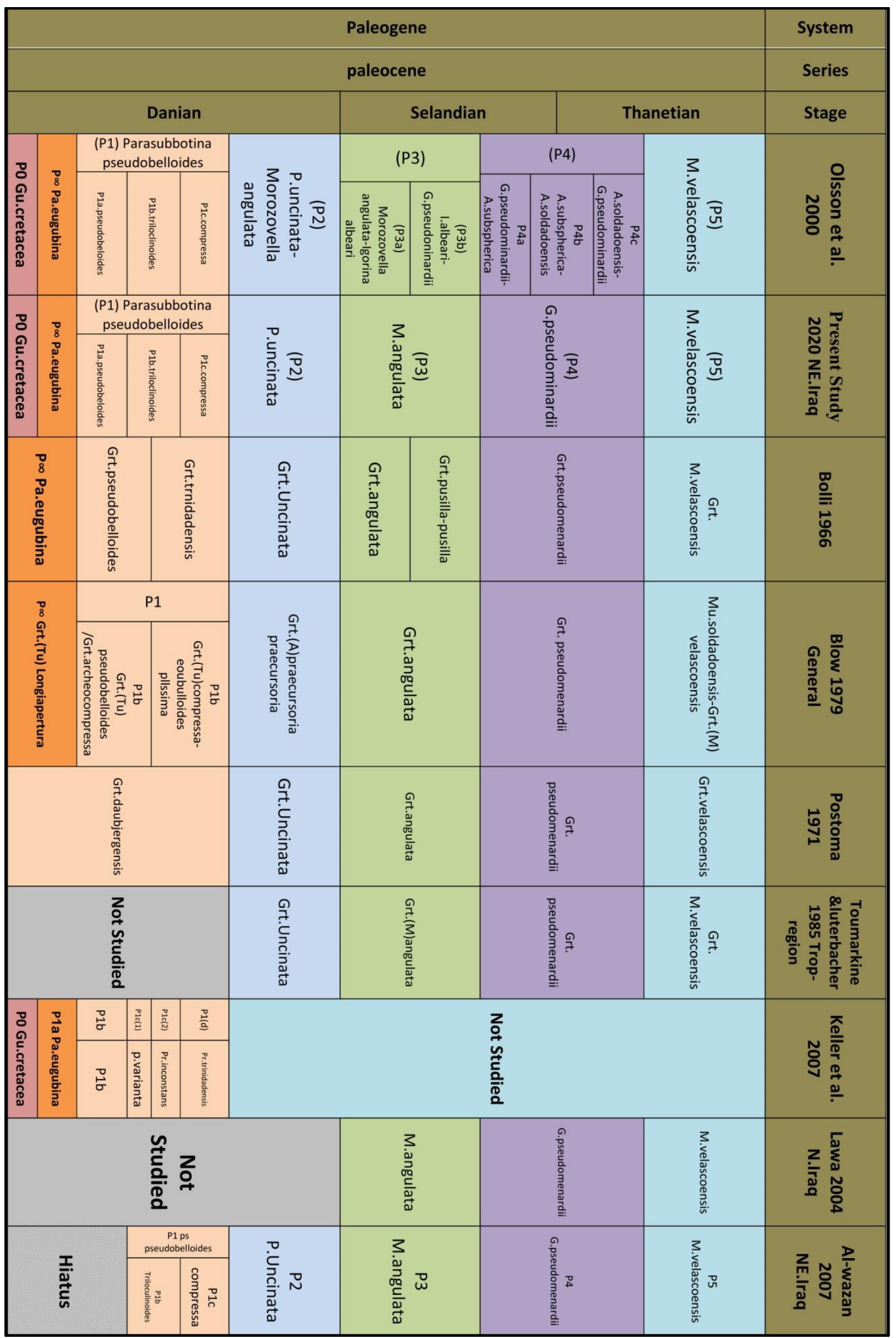

الثكل 6: مضاهاة الانطقة الحياتية للفورامنيفرا الطافية ضمن تكوين كولوش في الدراسة الحالية مع عدد من الدراسات خارج العراق. 


\section{Depositional Environment البيئة الترسيبية لتكوين كولوش}

يعد العمق البحري من العوامل البيئية المهمة التي تؤثر على توزيع الفورامنيفرا؛ وذلك بسبب ارتباطها الكبير خاصة القاعية منها بأعماق بحرية محددة، لذا تم الاعتماد على متحجرات الفورامنيفرا في دراسة وتحديد الأعماق البحرية القديمة وطبيعة الحوض الترسيبي، ولغرض تحديد الأعماق البحرية القديمة من خلال متحجرات الفورامنيفرا، تم تطبيق الدراسة الاحصائية من خلال للنسبة المئوية للفورامنيفرا الطافية على المجموع الكلي لحشود الفورامنيفرا (الطافية + القاعية) ضمن مقاطع الدراسة، حيث اوضحت دراسة كل من (Gibson, 1989) و ) Boersma, 1978) ان هذه النسبة المئوية تتغير مع العمق حيث تكون (50\%) في مناطق الرصيف الخارجي ( Outer) shelf وتصل الى (80\%) في منطقة المنحدر الاعلى (Upper slope) وتزداد الى (90\%) في منطقة المنحدر الاوسط (Middle slope)، فضلاً عن الاعتماد على الفورامنيفرا القاعية وتتوعها وانتشارها خلال اعماق مختلفة وتئة بسبب ارتباطها بالبيئة، مع الاخذ بنظر الاعتبار بعض الدراسات التي تناولت تحديد البيئات الترسيبية باستخدام

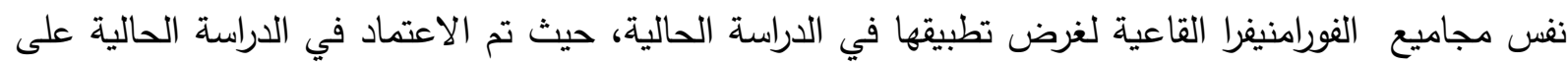

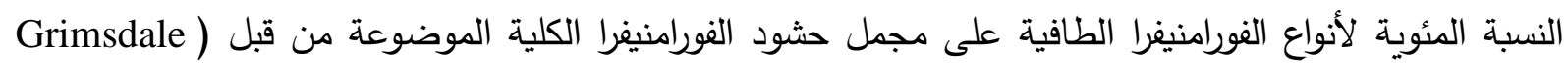

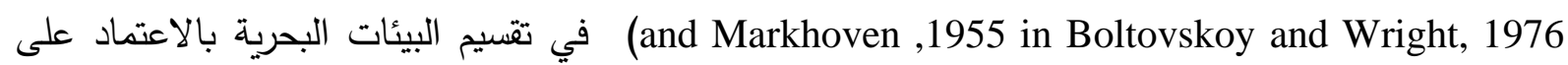
النسبة المئوية لأنواع الفورامنيفرا.

\section{البيئة الترسيبية لتكوين كولوش (مقطع ليناوا)}

تمثل النماذج من (1-24) بداية الجزء الاسفل من التكوين (الباليوسين المبكر) (P0-P1) حيث تمتاز بسيادة صخور المارل، وتزداد نسبة الفورامنيفرا الطافية على مجمل حشود الفورامنيفرا تدريجيا في النماذج الاولية والتي تبدأ من (50\%) الى ان تصل في نموذج رقم (14,15) الى (74\%) ثم تتراجع الى (52\%) في نموذج رقم (24)، ونلاحظ وفرة عالية للفورامنيفرا الطافية حيث تكون النسبة المئوية محصورة بين (50-74\%) وهذه النسبة تمثل الترسيب ضمن بيئة المنحدر العلوي (Upper slope) التي تكون محصورة بين الاعماق من (200-600) مترا، كما وتم تسجيل مجموعة اجناس من الفورامنيفرا القاعية التي توجد ضمن هذه الاعماق والبيئات وتثمل:

(Cibicidoides , Anomalinoides , Spiroplectammina , Dentalina, Lenticulina)

حيث اشارت دراسة (Al-Mutwali, 2000) لتكوين كولوش في شقلاوة الى ارتباط بعض انواع الفورامنيفرا القاعية ضمن هذه البيئة ومنها Cibicidoides alleni , Cibicidoides susanensis وشخص (Kouwenhoven et al.,1995) في تونس بعض الاجناس منها جنس (Anomalinoides) التابعة لنفس البيئة،

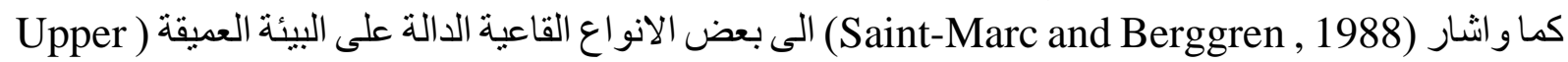
(slope في بحر التيش منها (Cibicidoides dayi , Spiroplectammina dentata)،كما وبين كل من (Anomalinoides, بعض الاجناس التي تعود الى الباثيال الاعلى ومنها (Widmark and Speijer, 1997)

.Lenticulina)

وتمثل النماذج من (25-29) نهاية الجزء الاسفل من تكوين كولوش والتي تمثل نطاق (P2)، وتتألف بشكل عام من الحجر الرملي الاخضر بالإضافة الى القليل من الطفل، وتقل في هذا الجزء اعداد الفورامنيفرا الطافية كما 
وتقل فيه نسبة الفورامنيفرا الطافية الى مجمل حشود الفورامنيفرا حيث تتراوح ما بين (33-35\%)، وهذه النسبة تمثل بيئة الرصيف الخارجي (Outer shelf) المحصورة بين الاعماق (100-200) مترا، كما وتم تسجيل مجموعة اجناس من الفورامنيفرا القاعية المستمرة من البيئة السابقة والتي توجد ضمن هذه الاعماق والبيئات وتشمل .(Cibicidoides, Anomalinoides, Spiroplectammina, Dentalina, Lenticulina, Pullenia) وتمثل النماذج (30-42) الجزء الاوسط من تكوين كولوش والمتمثل بالنطاق (p3) والتي تتكون بصورة عامة من صخور الطفل مع تداخلات بسيطة من صخور المارل، ونلاحظ تحسنا في الظروف البيئية انعكس ذلك على زيادة اعداد الفورامنيفرا الطافية في هذا الجزء، كما وتزداد نسبة الفورامنيفرا الطافية على مجمل حشود الفورامنيفرا تدريجيا في النموذج (30) حيث تكون (50\%) الى ان تصل في نموذج رقم (33) الى (71\%) ثم تتخفض تدريجيا الى (55\%) في نموذج رقم (42)، حيث تكون النسبة المئوية محصورة بين (50-71\%) وهذه النسبة تمثل الترسيب ضمن بيئة المنحدر العلوي (Upper slope) التي تكون محصورة بين الاعماق من (200-600) مترا كما وتم

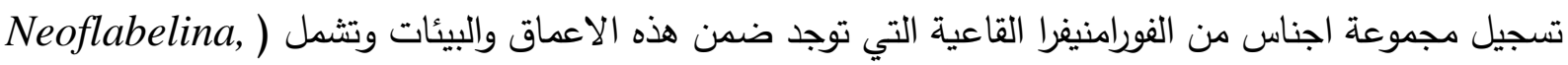
Cibicidoides (Nodosaria, Ammodiscus (, Anomalinoides , Spiroplectammina, Dentalina, Lenticulina , Pullenia الاجناس كل من (Berggern, 1974)، (Gibson, 1989)، (Al-Mutwali,2000) التابعة لهذه البيئة. بينما تسجل النماذج من (43-48) والتي تمثل بداية الجزء العلوي لتكوين كولوش تناقصا كبيرا في اعداد الفورامنيفرا الطافية، وتتكون من تعاقبات من صخور المارل والطفل تليها تعاقبات من الحجر الرملي والسلت، ويمثل هذا الجزء من التكوين نطاق (p4)، وتتناقص نسبة الفورامنيفرا الطافية على مجمل حشود الفورامنيفرا تدريجيا في النموذج (43) حيث تكون (33\%) الى ان تصل في نموذج رقم (48) الى (39\%)، حيث تكون النسبة المئوية محصورة بين هذه الارقام وهذه النسبة تمثل الترسيب ضمن بيئة الرصيف الخارجي (Outer shelf) التي تكون محصورة بين الاعماق من (100-200) مترا، كما وتم تسجيل مجموعة اجناس من الفورامنيفرا القاعية التي توجد ضمن هذه الاعماق والبيئات وتثمل:

Lenticulina, Pullenia, Neoflabelina, Nodosaria, Ammodiscus, Bulimina, Bolivina, Eponides, Lagina, Dorothia, Marsonella, Gavelinella, وبيّن (Koutsoukos and Hart, 1990) ان الأنواع التي تعود لجنس Gavelinella يكون ظهورها ضمن

$$
\text { بيئات الرصيفين الأوسط والخارجي. }
$$

ونلاحظ تزايدا ملحوظا في عدد انواع الفورامنيفرا الطافية مع تتاقص نسبي لأجناس الفورامنيفرا القاعية في النموذج (49) والذي يتكون من تعاقبات من صخور الطفل الاسود والحجر الرملي، والسبب يعود الى تيارات العكورة التي تمثل بيئة غير مستقرة للمجاميع القاعية، وكذلك تزداد نسبة الفورامنيفرا الطافية على مجمل حشود الفورامنيفرا لتمثل (63\%) وهذه النسبة تمثل الترسيب في بيئات بحرية عميقة (Upper slope) والتي تكون محصورة بالأعماق (200-600) مترا , وتم تسجيل مجموعة اجناس من الفورامنيفرا القاعية التي توجد ضمن هذه الاعماق والبيئات 
Lenticulina, Pullenia, Neoflabelina, Nodosaria, Ammodiscus, Bulimina, Bolivina, Eponides, Lagina, Dorothia, Marsonella, Gavelinella,

خلال النماذج (50-52) والتي تمثل الجزه الاخير من التكوين، والمتكونة من تعاقبات من الحجر الرملي والطفل، لوحظ تذبذب في الظروف الترسيبية مع ازدياد رواسب الحجر الرملي الناتج عن التراجع البحري ومله الحوض الرسوبي لتكوين كولوش حيث يمثل مناطق ترسيبية ضحلة، كما ونلاحظ انخفاض نسبة الفورامنيفرا الطافية وبالنتيجة تتخفض النسبة المئوية لها على مجمل حشود الفورامنيفرا حيث تكون (47\%) ثم تتخفض الى (18\%) في اخر نموذج في تكوين كولوش، وكذلك انخفاض في اعداد وانواع الفورامنيفرا القاعية بسبب تأثرها بالانقراض الذي حصل في الفترة مابين نهاية الباليوسين وبداية الايوسين في مناطق متفرقة في العالم (Thomas, 1996). تمثل النسبة المئوية هذه البيئة المحصورة بين الرصيف الخارجي (Outer shelf) الى الرصيف الاوسط ( Middle (تهين

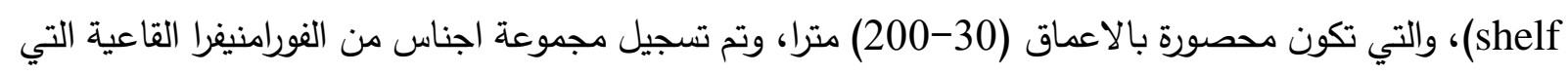

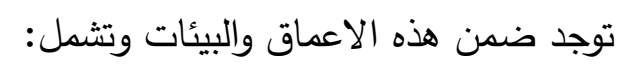

(Quinqueloculina, Dorothia, Repmanina, Oolina, Coryphostoma, Anomalinoides, Lenticulina , Nodosaria, Verneuilina).

حدد (Al-Mutwali, 2000) في شقلاوة بعض الاجناس القاعية الدالة على هذه البيئة الترسيبية منها جنس (Guinqueloculina)

وبناءا على كل ما سبق يمكن تقسير البيئة الترسيبية لتكوين كولوش في مقطع ليناوا ابتداءا من جزئه الاسفل حيث يكون الترسيب في مناطق الباثيال الأعلى، اما في الجزء الاوسط من التكوين فيكون الترسيب في منطقة الرصيف الخارجي، وينتهي الترسيب في جزئه الاعلى ضمن بيئة الرصيف الاوسط حيث يقل العمق الترسيبي

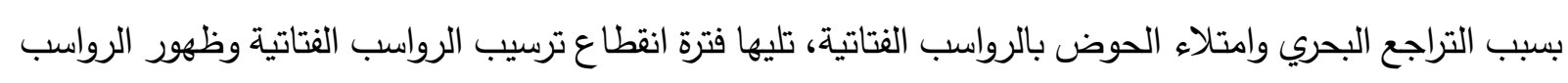
الجيرية ذات الترسيب الكيميائي المتمثلة بتكوين خورمالة (شكل 7).

\section{البيئة الترسيبية لتكوين كولوش (مقطع بادي)}

يظهر هذا المقطع اختلافا بسيطا عن مقطع ليناوا من حيث التركيب الصخري الذي يغلب عليه صخور الحجر الرملي بنسبة كبيرة وكذلك السلت، بينما تقل نسبة صخور الطفل وصخور المارل، كذلك قلة اعداد متحجرات الفورامنيفرا الطافية والقاعية.

تمثل النماذج من (2-14) الجزء الاسفل من المقطع وتتكون بصورة عامة من تعاقبات من الحجر الرملي والطفل مع طبقة قليلة السمك من صخور المارل متمثلة بالنموذج رقم (3) حيث تكون اعداد الفورامنيفرا الطافية والقاعية عالية جدا في هذا النموذج الذي يعكس ظروفا بيئية جيدة، حيث تكون النسبة المئوية للفورامنيفرا الطافية على مجمل حشود الفورامنيفرا في هذا النموذج (58\%) والتي تمثل بيئة الباثيال او المنحدر الاعلى ( Upper

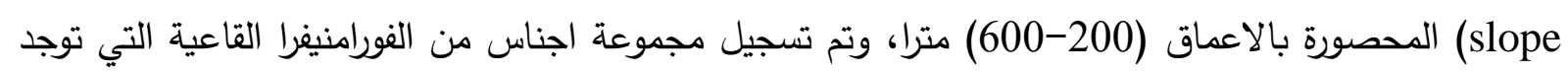
ضمن هذه البيئات وتثمل: (Senticulina, Dentalina, ) (Spiroplectammina) وتقل اعداد الفورامنيفرا من النموذج (4) لغاية النموذج (12) ويلاحظ انخفاض النسبة 
المئوية لتتراوح مابين (45-38\%)، وتؤشر هذه النسبة الترسيب ضمن بيئة الرصيف الخارجي (outer shelf)، وهنا يؤشر الترسيب حالة من التضحل حيث تم تشخيص بعض الاثار للمتحجرات بشكل حفر سكنية كذلك اوراق نبات بثكل طابع على الصخور بالاضافة الى بقايا اصداف للمحاريات، وحالة التضحل في الترسيب نتيجة انخفاض مستوى سطح البحر النسبي مترافقة مع تزويد وتجمع رسوبيات فتاتية لأن الحفر العمودية ربما تعود للجنس الآثاري (Skolithos) في النموذجين (13-14) اللذين شهدا ارتفاعا ملحوظا في اعداد الفورامنيفرا وتحسنا في الظروف البيئية وارتفاع نسبة الفورامنيفرا الطافية على مجمل حشود الفورامنيفرا التي وصلت الى (65\%) والتي تمثل الترسيب ضمن بيئة الباثيال الاعلى مع وجود نفس المجموعة من اجناس الفورامنيفرا القاعية التي تمثل هذه الاعماق.

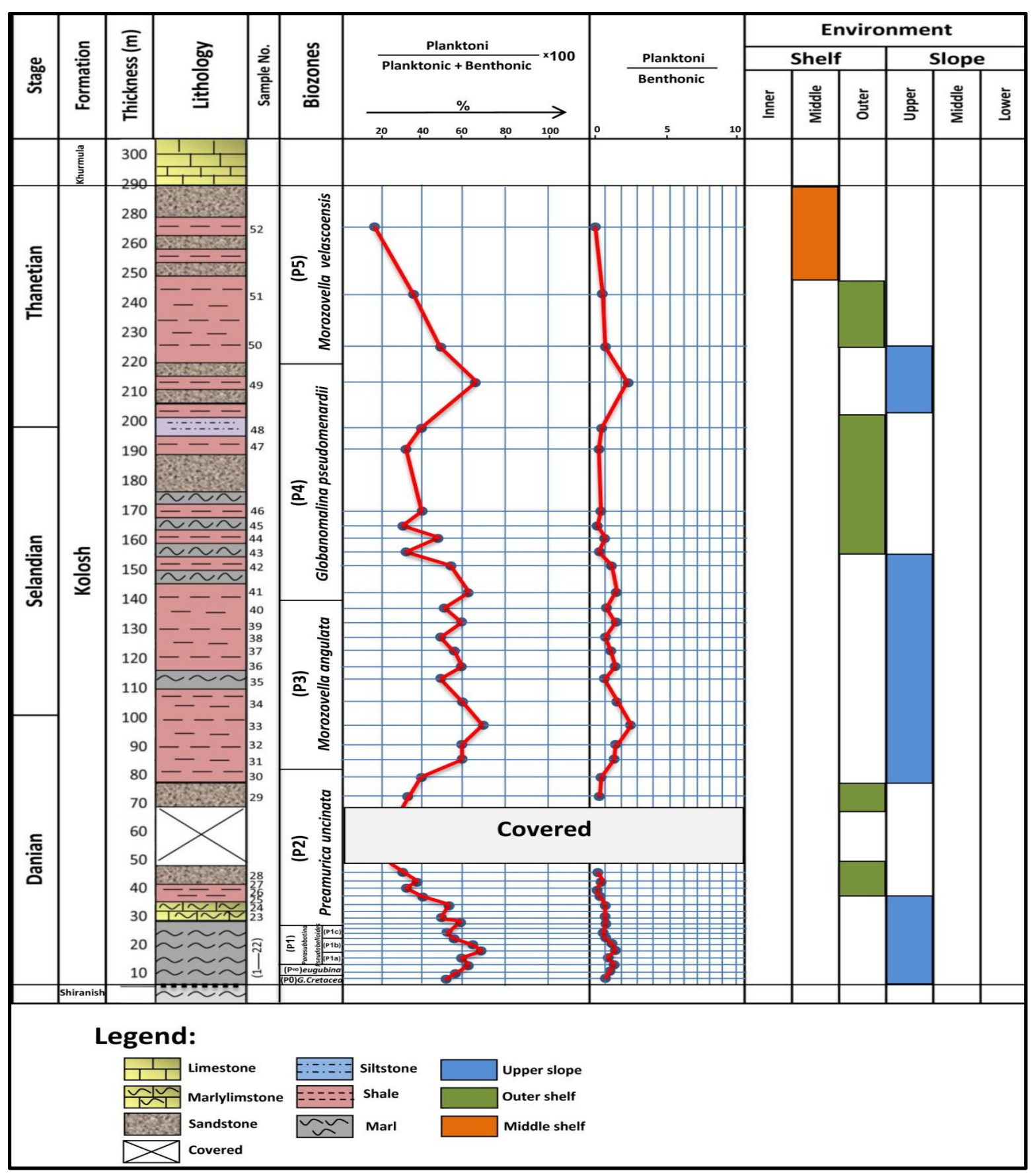

الثكل 7: البيئة الترسيبية لتكوين كولوش في مقطع ليناوا. 
خلال النماذج (15-20) والتي تمثل الجزء الاوسط من التكوين فانها تتألف من تعاقبات من الحجر الرملي وصخور الطفل، نلاحظ تذبذبا في الظروف البيئية حيث تقل اعداد الفورامنيفرا الطافية تدريجيا وتصل النسبة المئوية للفورامنيفرا الطافية على مجمل حشود الفورامنيفرا الى (38\%) في النموذج (17) ثم يعقبها ارتفاع في النموذج (19) لتبلغ النسبة فيه (69\%). هذا التذبذب يعكس بيئات ترسيبية مختلفة تتمثل بالرصيف الخارجي ثم يزداد العمق الترسيبي الى ان يصل بيئة الباثيال الاعلى اي بالاعماق المحصورة بين (100-200) مترا ثم مايزيد عن عمق (200) مترا، كما وتم تثخيص مجموعة اجناس من الفورامنيفرا القاعية التي توجد ضمن هذه البيئات وتثمل: Neoflabelina, Ammodiscus, Lenticulina, Bulimina, Eponides, Bolivina, Lagina, ) (Dorothia, Gavelinella, Marsonella حيث نلاحظ في هذا الجزء تداخل اجناس الفورامنيفرا القاعية وتذبذبها من الانواع الدالة على البيئة العميقة مثل Giusberti et al., 2015) Gavelinella) الى الانواع التي تثير الى البيئة الاقل عمقا مثل Lenticulina) Al-Mutwali, 2000) Bulimina , بعض اجناس مناطق الرصيف البحري الضحل الى المناطق البحرية الاكثر عمقا. اظهرت النماذج (21-35) التي تمثل الجزء العلوي من ترسبات تكوين كولوش انخفاضا تدريجيا في اعداد الفورامنيفرا الطافية والقاعية ناتجا عن ظروف بيئية غير ملائمة للمعيشة، حيث لوحظ تباين وانخفاض تدريجي في

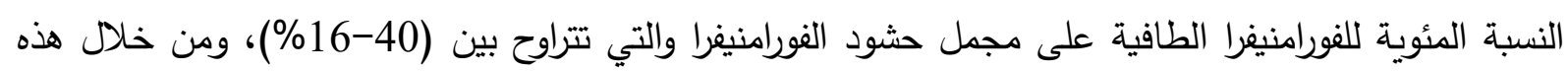
Outer-Middle ) النسبة تبين ان هذا الجزء قد ترسب ضمن منطقة الرصيف الخارجي الى الرصيف الاوسط shelf)، كما وتم تشخيص مجموعة اجناس من الفورامنيفرا القاعية التي توجد ضمن هذه البيئات وتثمل .(Quinqueloculina sp., Coryphostoma, Verneuilina, Oolina, Anomalinoides, Nodosaria) سجل البعض من هذه الاجناس ضمن نفس البيئة (Petters, 1979) في نيجيريا والتي تعتبر دليلا على البيئات الضحلة ذات المناخ الاستوائي.

يتضح مما سبق انه يمكن تقسير البيئة الترسيبية لتكوين كولوش في مقطع بادي ابتداءا من جزئه الاسفل حيث يكون الترسيب في مناطق الباثيال الاعلى وتعكس ذلك رواسب صخور المارل والطفل التي تترسب في بيئات عميقة ماعدا جزء قليل يمتد الى بيئة الرصيف الخارجي، وتزداد رواسب الحجر الرملي في الجزء الاوسط من التكوين بنسبة اكبر من مقطع ليناوا مع القليل من الطفل وهذا الجزء يمثل الترسيب في منطقة الرصيف الخارجي ويتذبذب قليلا مع بيئة المنحدر الأعلى، ويكون الترسيب في جزئه الاعلى ضمن بيئة الرصيف الخارجي-الرصيف الاوسط حيث يقل العمق الترسيبي بسبب التراجع البحري وامتلاء الحوض بالرواسب الفتاتية وظهور الرواسب الجيرية ذات الترسيب الكيميائي المتمثلة بتكوين خورمالة (شكل 8). 
سيف صالح محمد الخليف ماجد مجدي عبدالمجيد المتولي

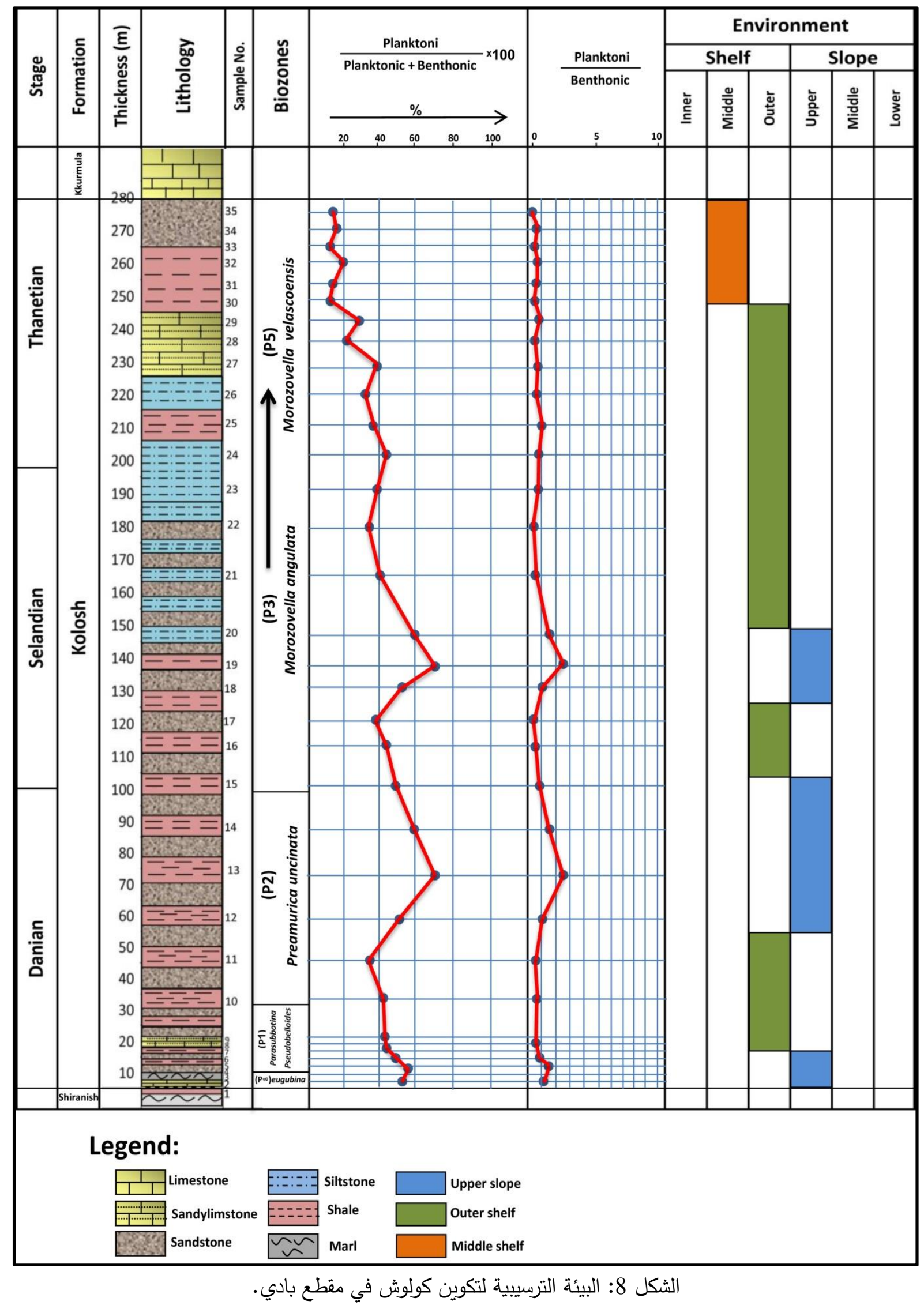




\section{Sequence Stratigraphy الطباقية التتابعية}

تقسر طباقية التابع التاريخ الترسيبي لتكوين كولوش في مقاطع الدراسة على اساس علم طباقية التتابع الرابط

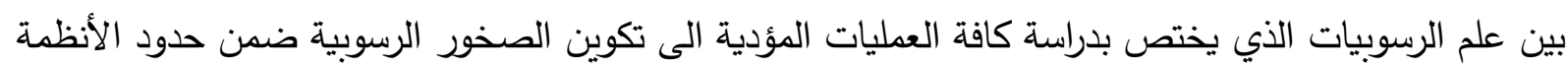

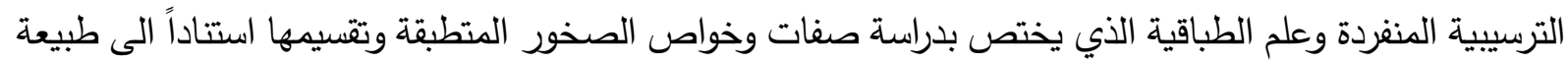

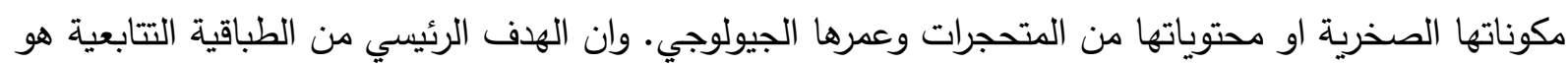
العمل على تقسيم تتابعات الصخور إلى حزم (sets) وكل حزمة تمثل دورة ترسيبية خلال وقت معين شهدت خلالها

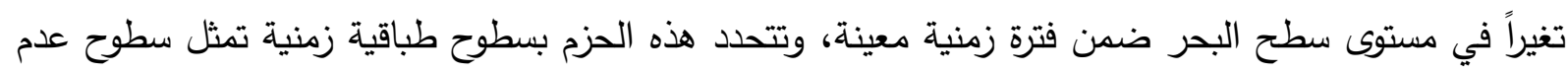

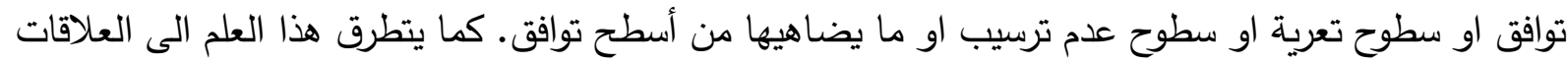

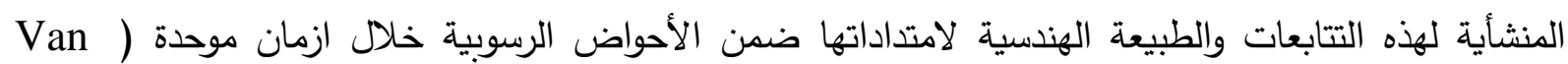
.(Wagoner et al., 1995

\section{طباقية التتابع لتكوين كولوش مقطع ليناوا}

تمتد تتابعات تكوين كولوش في مقطع ليناوا بعر الباليوسين واستغرق ترسييها فترة زمنية تقدر بحوالي ( 10 Ma

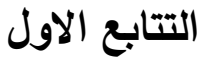

يتمثل هذا التتابع بالجزء الاسفل من تكوين كولوش وتحديدا ضمن الانطقة من (P0) الى نهاية (P2) ممثلا

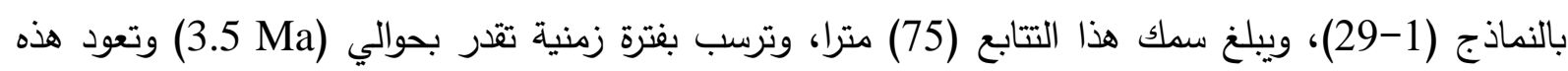

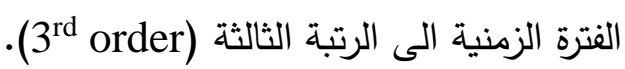
يبدأ هذا التتابع بمسار النظام التقدمي (Transgression System Tract) الذي يحده من الأسفل الحد الندان الفاصل بين عصري الكريتاسي والباليوجين، علما اننا لم نلاحظ وجود تتابعات المسار الواطئ (Low system)

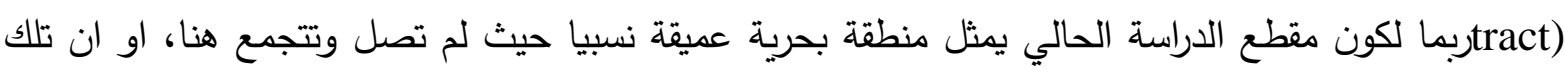

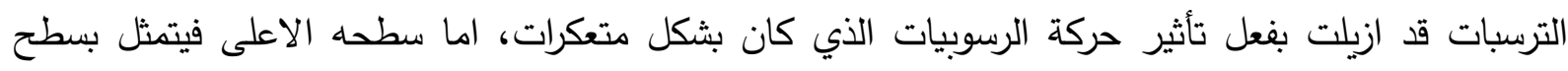
الفيضان الاعظم (Maximum Flooding Surface) وتمثلت ترسباته بصخور المارل التي يبلغ سككها (20)

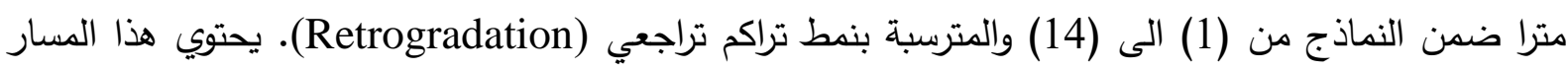
على نسبة عالية من الفورامنيفرا الطافية، كما ان النسبة المئوية للفورامنيفرا الطافية على مجمل حشود الفئل الفورامنيفرا تكون عالية ايضا، وتستمر الظروف الترسيبية وصولا الى اعلى تعمق في الرواسب عند سطح الفيضان الاعظم المثبت وجوده عند السمك (20) مترا ضمن النموذج (14)، كما وتم تثخيص الدقطع المكثف ( Condensed

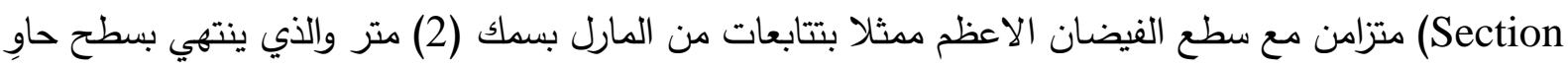

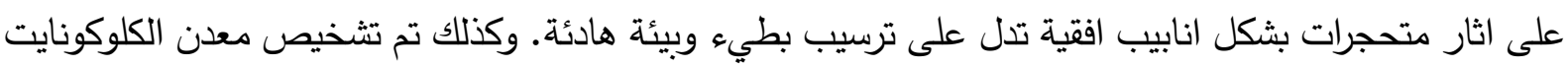
الذي يعتبر أحد الادلة على المقطع المكثف (Emery and Myers, 1996) يتبعلُ مسار النظام العالي ( (Stand System Tract

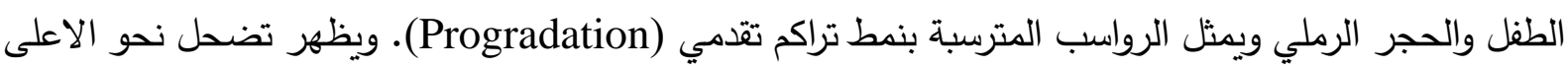


متمثلا برواسب الحجر الرملي، وتقل فيه نسبة الفورامنيفرا الطافية وكذلك النسبة المئوية للفورامنيفرا الطافية على مجمل حشود الفورامنيفرا وصولا الى حد تتابع من نوع (-Type -2) عند السمك (70) مترا والنموذج (29) الذي ولي يمثل نهاية التتابع.

\section{التتابع الثاني}

يتمثل هذا التتابع بالجزء الاوسط من تكوين كولوش وتحديدا ضمن الانطقة من (P3) الى منتصف (P4)، ويبلغ سمك هذا التتابع (120) مترا ضمن النماذج (30-47)، وترسب بفترة زمنية تقدر بحوالي (3.3 Ma) وتعود هذه الفترة الزمنية الى الرتبة الثالثة (3rder order).

يبدأ هذا التتابع بمسار النظام التقدمي الذي يحده من الاسفل حد تتابع من النوع -Type -2، اما سطحه الاعلى فيتمثل بسطح الفيضان الاعظم وتمثلت ترسباته بصخور الطفل التي يبلغ سمكها (25) مترا ضمن النماذج من (30) الى (33) والمترسبة بنمط تراكم تراجعي. يحتوي هذا المسار على نسبة عالية من الفورامنيفرا الطافية، كما ان النسبة المئوية للفورامنيفرا الطافية على مجمل حشود الفورامنيفرا تكون عالية ايضا، وتستمر الظروف الترسيبية وصولا الى اعلى تعمق في الرواسب عند سطح الفيضان الاعظم عند السمك (100) متر في النموذج (33)، يتبعهُ مسار النظام العالي الذي يتكون من تعاقبات من صخور الطفل والمارل وتعاقبات من الحجر الرملي بسمك (95) مترا ضمن النماذج من (34) الى (47) ويمثل الرواسب المترسبة بنمط تراكم تقدمي. ويظهر تضحل نحو الاعلى متمثلا برواسب الحجر الرملي. ويحد هذا المسار من الاسفل سطح الفيضان الاعظم ومن الاعلى حد التتابع نوع (Type -2-)، وتقل فيه نسبة الفورامنيفرا الطافية تدريجيا نحو الاعلى وكذلك تقل النسبة المئوية للفورامنيفرا الطافية على مجمل حشود الفورامنيفرا وصولا الى حد تتابع من نوع (-Type -2) عند السمك (190) مترا الذي يمثل نهاية التتابع.

\section{التتابع الثالث}

يتمثل هذا التتابع بالجزه الاعلى من تكوين كولوش وتحديدا ضمن الانطقة من منتصف (P4) الى نهاية (P5) ممتدا ضمن النماذج من (48) الى (52). ويبلغ سمك هذا التتابع (85) مترا، وترسب بفترة زمنية تقدر بحوالي (3.4 Ma) وتعود هذه الفترة الزمنية الى الرتبة الثالثة (3ن) (3ن).

يبدأ هذا التتابع بمسار النظام التقدمي الذي يحده من الاسفل حد تتابع من النوع -Type -2، اما سطحه الاعلى فيتمثل بسطح الفيضان الاعظم وترسباته من صخور الطفل والسلت ويبلغ سمكها (20) مترا ضمن النماذج من (48) الى (49) والمترسبة بنمط تراكم تراجعي. يحتوي هذا المسار على نسبة عالية من الفورامنيفرا الطافية كذلك النسبة المئوية للفورامنيفرا الطافية على مجمل حشود الفورامنيفرا تكون عالية أيضا. وتستمر الظروف لألتئ الترسيبية وصولا الى اعلى تعمق في الرواسب عند سطح الفيضان الاعظم عند السمك (215) مترا في النموذج (49) يتبعهُ مسار النظام العالي الذي يتكون من تعاقبات من صخور الطفل والحجر الرملي بسمك (65) مترا ويمثل الرواسب المترسبة بنمط تراكم تقدمي ويظهر تضحلا نحو الاعلى متمثلا برواسب الحجر الرملي، وتقل فيه نسبة الفورامنيفرا

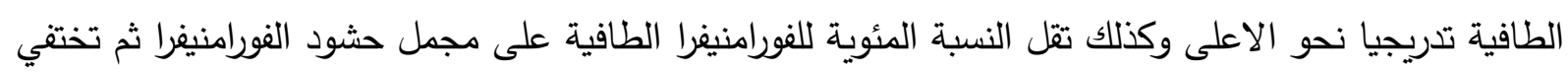
نحو الاعلى وصولا الى طبقات الحجر الجيري التي تمثل نهاية تتابعات تكوين كولوش وبداية ترسيب تتابعات تكوين خورمالة التي تمثل استمرارا لنظام المسار العالي لهذا التتابع (شكل 9). 


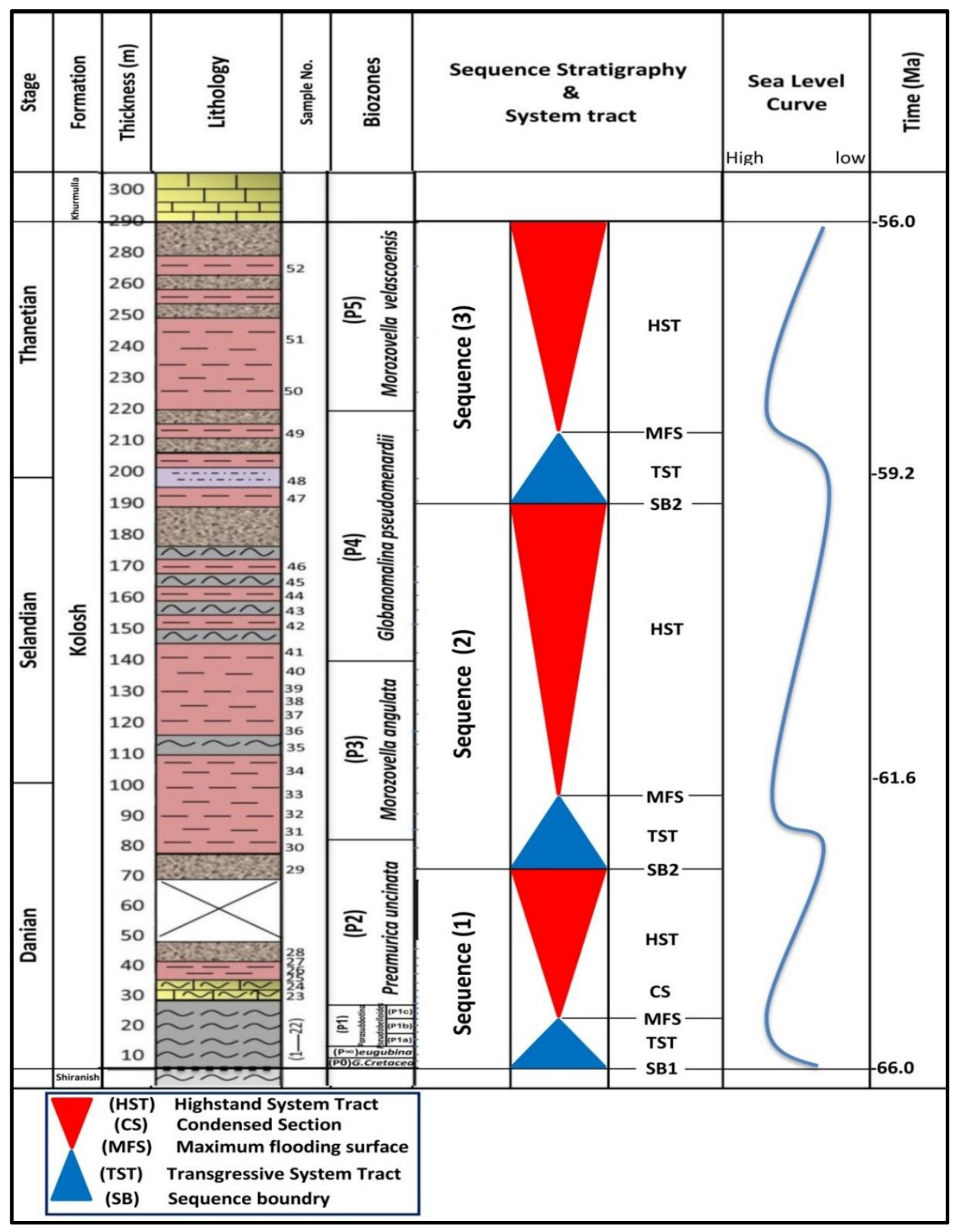

الثكل 9: الطباقية التتابعية لتكوين كولوش مقطع ليناوا.

\section{طباقية التتابع لتكوين كولوش مقطع بادي}

تمتد تتابعات تكوين كولوش في مقطع بادي بعدر الباليوسين واستغرق ترسيبها فترة زمنية تقدر بحوالي ( 10 Ma )، وتضمن هذا التتابع ثلاث دورات تتابعية من الاسفل الى الاعلى كما يلي:

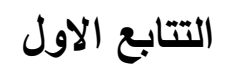

يتمثل هذا التتابع بالجزء الاسفل من تكوين كولوش ضمن الانطقة من (P0) الى بداية (P2). ويبلغ سمك هذا التتابع (45) مترا ضمن النماذج من (2) الى (11)، وترسب بفترة تقدر بحوالي (2.8 Ma) وتعود هذه الفترة الزمنية الى الرتبة الثالثة (3rder order). 
يبدأ هذا التتابع بمسار النظام التقدمي الذي يمثل حده الاسفل حد الكريتاسي - الثلاثي وهو يمثل حد تتابع

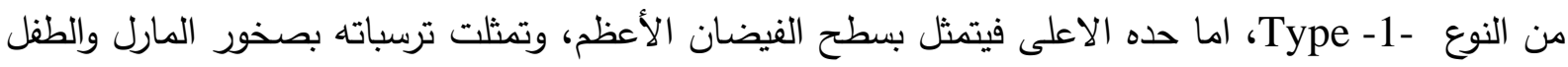

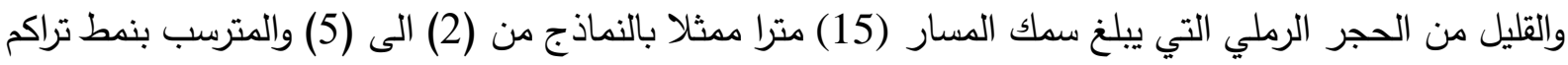

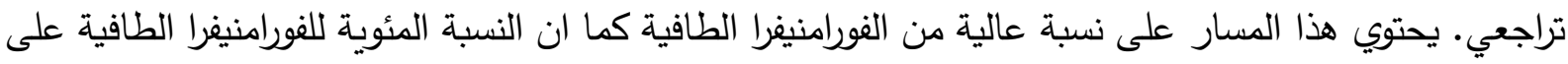

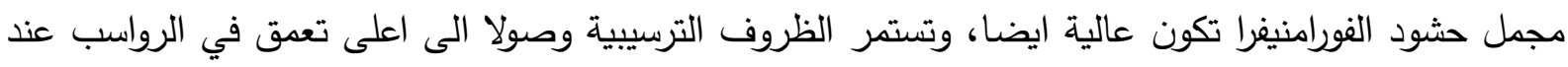

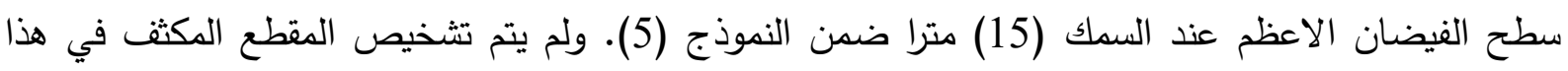

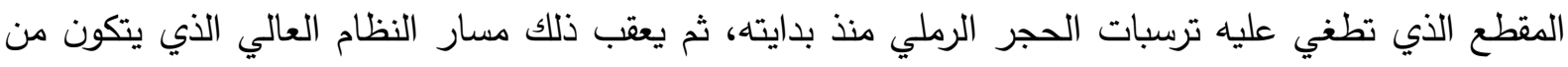

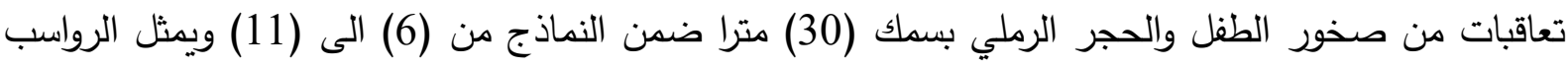
المترسبة بنمط تراكم تقدمي ويظهر تضحلا نحو الاعلى متمثلا برواسب الحجر الرملي، وتقل فيه نسبة الفورامنيفرا

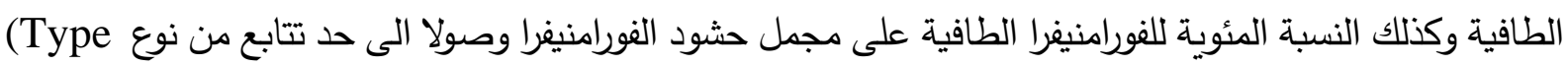
(-2- عند السمك (45) مترا ضمن نموذج (11) الذي يمثل نهاية التتابع.

\section{التتابع الثاني}

يتمثل هذا التتابع بالجزء الاوسط من تكوين كولوش وتحديدا ضمن الانطقة من (P2) الى بداية (P3)، ويبلغ

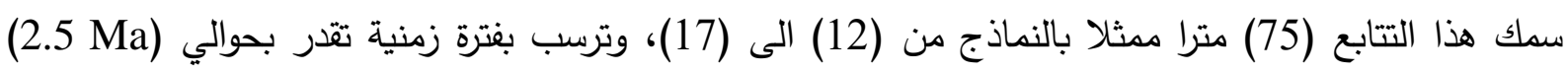

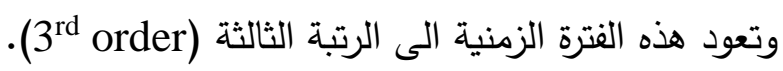

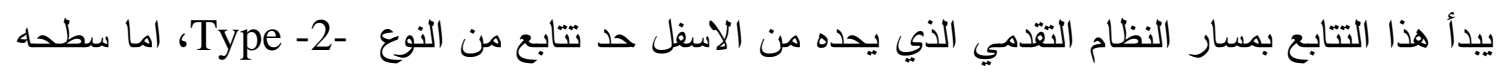

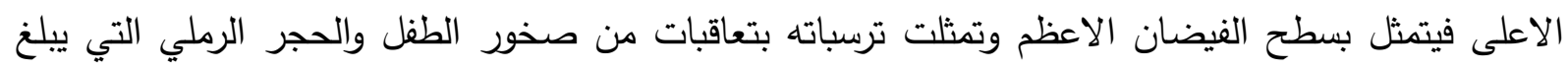

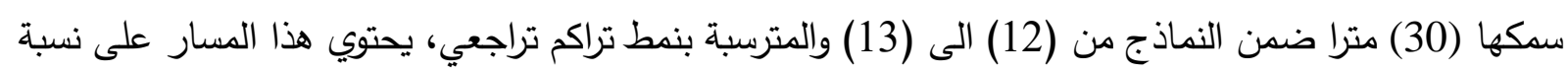

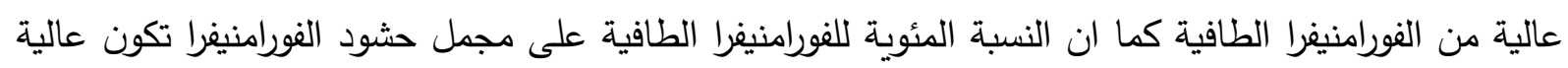

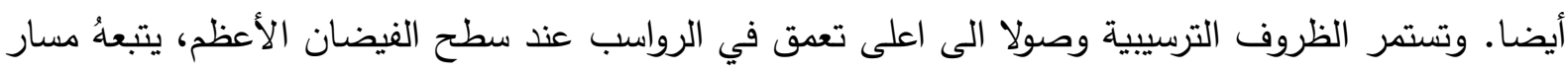

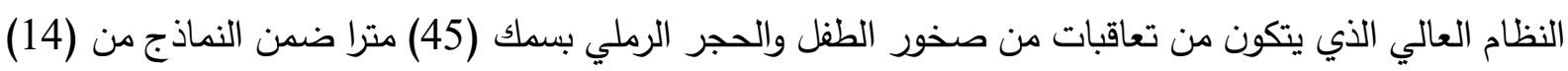

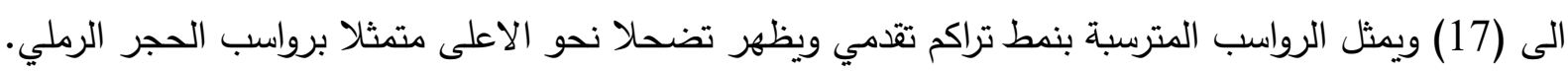

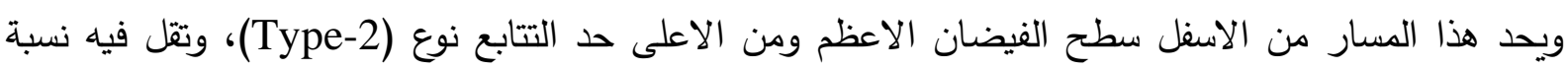

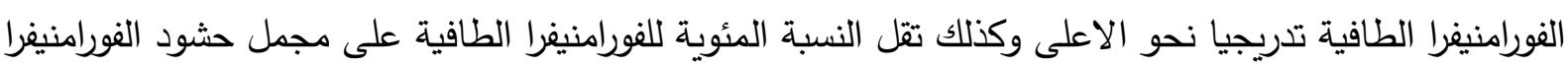
وصولا الى حد تتابع من نوع (-Type -2) الذي يمثل نهاية التتابع.

\section{التتابع الثالث}

يتمثل هذا التتابع بالجزء الاعلى من تكوين كولوش ضمن الانطقة من منتصف (P3) الى نهاية (P5)، (P5)،

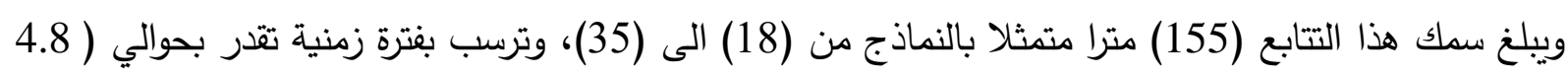

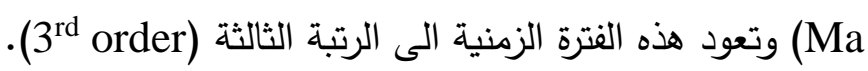

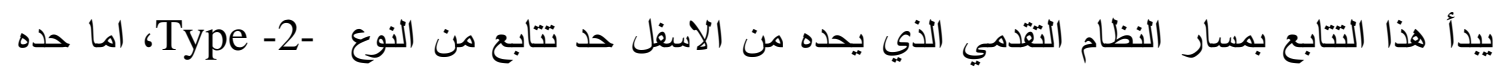

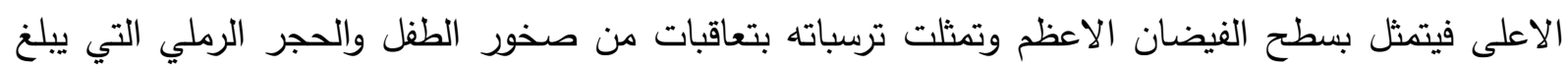

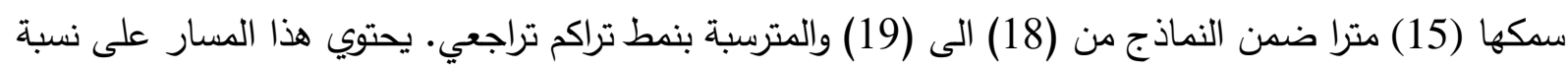


عالية من الفورامنيفرا الطافية كذلك النسبة المئوية للفورامنيفرا الطافية على مجمل حشود الفورامنيفرا تكون عالية ايضا، وتستمر الظروف الترسيبية وصولا الى اعلى تعمق في الرواسب عند سطح الفيضان الأعظم، يتبعهُ مسار النظام العالي الذي يتكون من تعاقبات من صخور الطفل والسلت والحجر الرملي بسمك (140) مترا ويمثل الرواسب التب المترسبة بنمط تراكم تقدمي ويظهر تضحلا نحو الاعلى الذي يتمثل برواسب الحجر الرملي، وتقل فيه نسبة الفورامنيفرا الطافية تدريجيا نحو الاعلى وكذلك تقل النسبة المئوية للفورامنيفرا الطافية على مجمل حشود الفورامنيفرا ثم تختفي نحو الاعلى وصولا الى طبقات الحجر الجيري التي تمثل نهاية تتابعات تكوين كولوش وبداية ترسيب تتابعات تكوين خورمالة التي تمثل استمرارا لنظام المسار العالي لهذا التتابع (شكل 10).

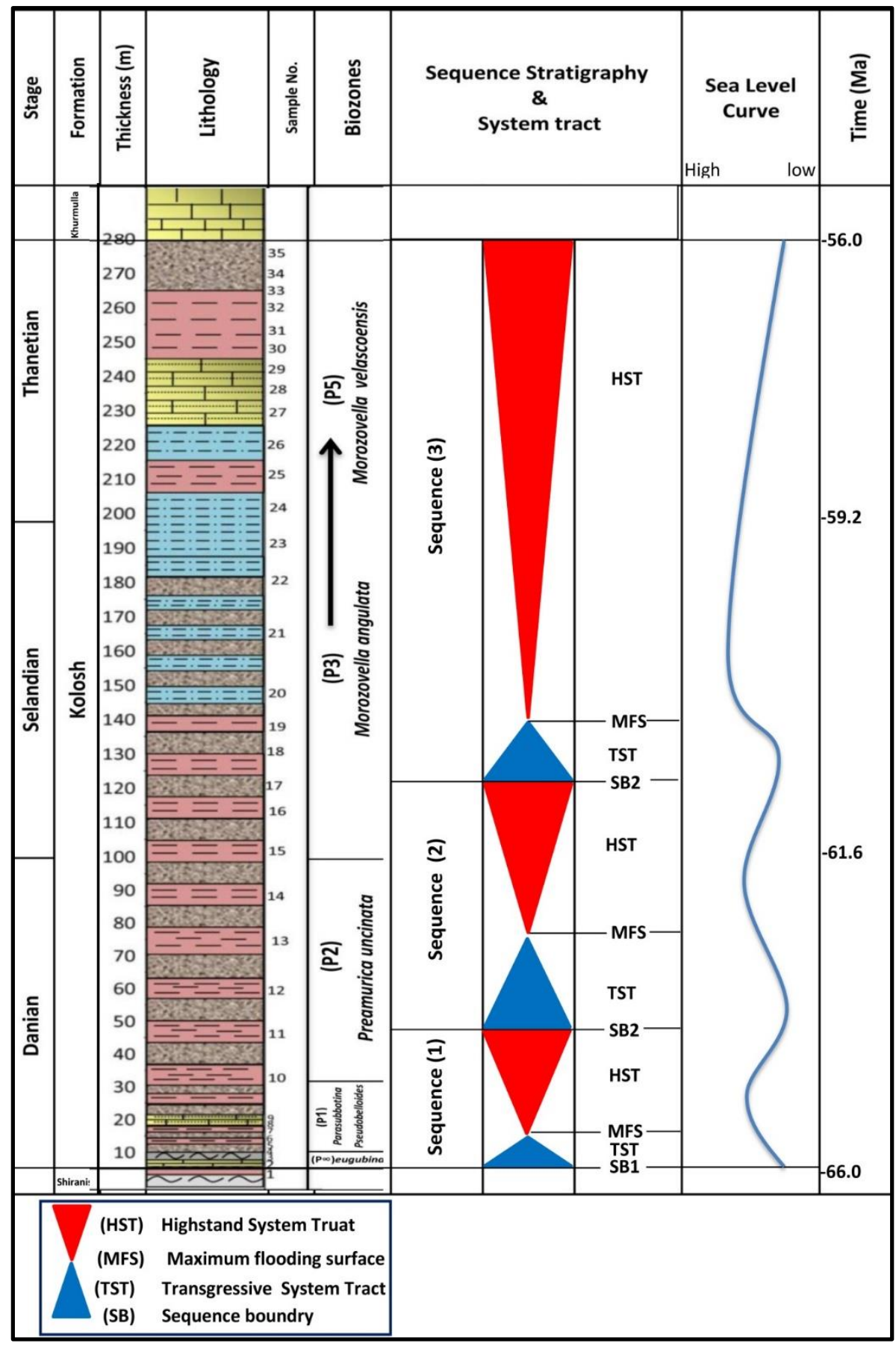

الشكل 10: الطباقية التتابعية لتكوين كولوش مقطع بادي. 


\section{مناقثة عامة للطباقية التتابعية لتكوين كولوش في مقطعي الدراسة}

1- تم تثبيت ثلاث دورات طباقية تتابعية في المقطعين ولكن تختلف مواقع الحدود واسـطح الطغيان بينهما قليلا وتعزى اسـباب ذلك الى الاختلاف في طبيعة الترسـبات وكذلك الاختلاف في كمية حشـود المتحجرات التي تميزت بكثرتها في مقطع ليناوا وقلتها في مقطع بادي، لذلك عملية تحديد الدورات في مقطع ليناوا كان هو

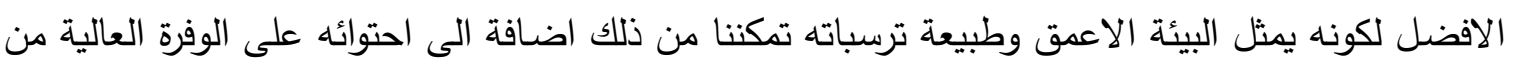

انواع الفورامنيفرا الطافية والقاعية.

2- ان اول سـطح طغيان بحري (Maximum Flooding Surface) في المقطعين حدث تقريبا بنفس الزمن ولكن حد التتابع (SB) بين تعاقب (1) و(2) ظهر زمنيا في مقطع بادي قبل مقطع ليناوا حيث ان مقطع بادي على العموم كان هو الاضـحل او الاقل عمقا من مقطع ليناوا وهذا من المحتمل ان يكون السبب لعدم ظهور ترســـبات الدانيان المبكر (P0) في مقطع بادي، وكذلك الحال بين تعاقب (2) و (3). ولذلك كان تمييز التعاقبات اكثر وضـــوحا في مقطع ليناوا، ومما يؤكد هذا الكلام هو ظهور ســــح الطغيان الاعظم الثاني في مقطع بادي قبل مقطع ليناوا، وهذا يدل على ان مجال الاســتيعاب في مقطع بادي اقل من مقطع ليناوا، وكذلك الحال بالنسبة لسطح الطغيان الاعظم الثالث. 3- ترسبات النظام العالي (High Stand System Tract) لآخر تعاقب شمل سـكا كبيرا وفترة زمنية طويلة في مقطع بادي (140 m) اكثر من مقطع ليناوا (65 m) والسبب يعود الى كون مقطع بادي تلقى ترسبات رملية اكبر حجما من الترسـبات الناعمة المتجمعة بصــورة اكثر في مقطع ليناوا بســبب ان تيارات العكورة ترسب الرسوبيات الخشنة في المناطق الأقرب للساحل (Proximal) والترسبات الطينية الناعمة في المناطق الأبعد والأعمق نسـبيا (Distal areas)، لذلك فأن عملية المله لمجال الأسـتيعاب كانت اسـرع في مقطع بادي مما هي عليه في مقطع ليناوا وذلك ادى الى الترسـيب الكبير الســك ضـــمن مســار النظام العالي خصوصا في فترة اعلى هذا المقطع حيث كانت هناك عملية تراجع بحري متزامنة مع عملية الترسيب.

\section{Conclusions الاستنتاجات}

1- تم استنتاج البيئة الترسيبية لتكوين كولوش في مقاطع الدراسة بالاعتماد على طبيعة حشود الفورامنيفرا الطافية

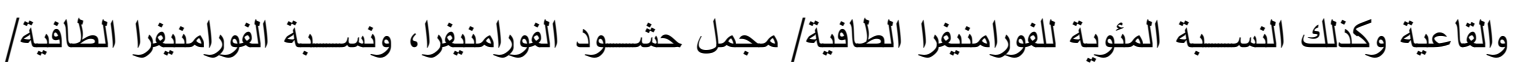

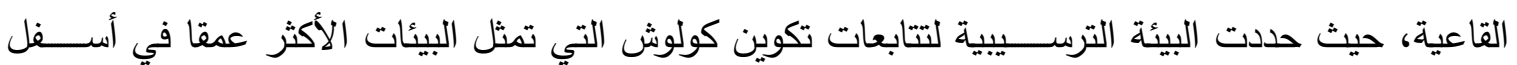
التكوين ممثلة ببيئات الباثيال والرصيف الخارجي لتصبح بعدئذ اقل عمقا ضمن الرصيف الأوسط في اجزائه العليا.

2- تم تقســيم تكوين كولوش في مقاطع الدراســة الى ثلاث دورات تتابعية حيث تمثل كل دورة تتابع من الرتبة

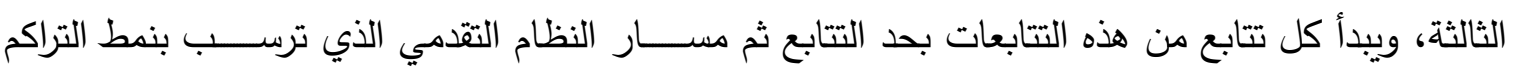
التراجعي وصولا الى سطح الفيضـان الاعظم ويعقبه مسار النظام العالي الذي تمثل ترسباته النمط التراكمي التقدمي خلال مرحلة الهجوط النسبي في مستوى سطح البحر ـ كذلك تم تمييز ثلاثة أسطح للفيضـان الاعظم خلال ترسيب تكوين كولوش، فبالنسبة لمقطع ليناوا سطح الفيضان الاول عند نطاق (P1) بعمر (65 Ma) 
والثاني عند نطاق (P3) بعمر (51.3 Ma) والثالث عند نهاية نطاق (P8) (P) بعمر (ما مقطع

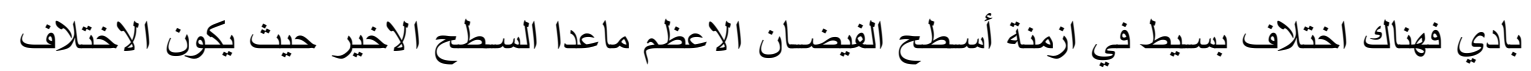
أكبر قليلا. ومن المقارنة للطباقية التتابعية للمقطعين ومطابقة الحدود الفاصلة لكل دورة تتابعية وكذلك سطح الفيضــان الاعظم تبين ان ترسـبات تكوين كولوش في مقطع بادي أكثر ضــــالة في اغلب فترات ترسـيبه مقارنة مع مقطع ليناوا الذي يمثل بيئة بحرية أعمق نوعا ما وبنعكس ذلك على طبيعة ترسبات كل مقطع. المصادر الأجنبية

Al-Mutwali ,M. M., 2000: Paleocene-Early Eocene Benthic foraminiferal Biostratigraphy and Paleoecology of kolosh formation, Shaqlawa Area, Northeast Iraq, Vol.1, pp.12-24.

Berggren, W.A. 1974: Late Paleocene - Eocene benthonic foraminiferal biostatigraphy, and paleoecology of Rockall Pank, Micropaleontology 20 (4), pp. 426-448.

Berggren, W.A. and Aubet, J., 1975: Paleocene benthonic foraminiferal biostatigraphy, Paleobiostatigraphy and paleoecology of Atlantic-Tethyan regions, Midway type fauna, Palaeogeography, Paleoclimatology, Paleoecology, Vol. 18, pp. 73-192.

Boersma, A., 1978: Foraminifera, In: B. V. Haq and A. Boersma (Eds.), Introduction to Marine Micropaleontology. Amsterdam, Elsevier, pp. 19-77.

Boltovskoy, E. and Wright, R., 1976: Recent Foraminifera. Dr. W. Junk, B.V. Puplishers, The Hague, $515 \mathrm{P}$.

Dunnington, H. V., 1955. The Tertiary . Cretaceous boundary problem in N. Iraq. No IR/ HVD/ 611. Baghdad. INOC Library, Un published report. Pp.1-66,figs1-3.

Dunnington, H. V., 1957. The Paleocene .Cretaceous unconformity at Aqra. Un published report.ivo. IR/ MUD /691. INOC Library.Baghdad,

Emery, D. and Myers, K., 1996: Sequence stratigraphy. Blackwell Science Ltd., 297P.

Gibson, T.G., 1989: Planktonic benthonic foraminiferal ratios: Modren patterns and tertiary applicability. Marine Micropalentology, V.15, 29-52P.

Giusberti L., Galazzo, F., Thomas, E., 2015 : Benthic foraminifera at the Paleocene/Eocene thermal maximum in the western Tethys (Forada section): variability in climate and productivity, pp. 4205-4272.

Jassim, S.Z. and Goff, J.C., 2006: Geology of Iraq. Published by Dolin, Prague and Moravian Mus. Brno, 341P.

Kouwenhoven, T,J. et al , 1995 , Benthic foraminiferal assemblages between two major extinction events: the Paleocene El Kef section, Tunisia , pp. 105-127.

Koutsoukos , Amery and Hart Miall , 1990: Cretaceous foraminiferal morphogroub distrubution pattern paleocommunities and trothic structure , v.81, pp.221-246

Olsson, R.K., Hemleben, C. Berggren, W.A. \& Huber, B.T., 2000: Atlas of Paleocene Planktonic Foraminifera.No.85, 252p, with 71 plates, 2 charts.and 29 paleogeographic mapes. 
Petters, S.W., 1979: Maastrichtian -Paleocene foraminifera from NW Nigeria and their paleogeography, Acta Palaeontologica polonica, Vol. 23, No. 2, pp. 131-154.

Saint- Marc, P. and Berggren, W., 1988: Aquanntitive analysis of Paleocene benthic foraminiferal assamblages in Central Tunisia. Journal of Foraminiferal Research, Vol. 18, No. 2, pp. 97-113.

Thomas, E., 1996 : The Paleocene-Eocene Benthic Foraminiferal Extinction and Stable Isotope Anomalies, pp.401-441.

Van Wagoner, J.C., Posamentier, H.W., Mitchum, R.M., Vail, R.R., Sarg, J.F., Loutit, T.S. and Hardenbol, J., 1995: An overview of the fundamentals of sequence stratigraphy and key definitions. In: Wligus, C.K. Hastings, B.S., Kendall, C.G., St. C. Posamentier, H.W., Ross, C.A. \& Wagoner, H.W. Van (eds.): Sea-level changes: An integrated approach, Society of Economic Paleontologists and Mineralogists, special publication, Vol. 42, pp. $39-45$.

Widmark, J. G., \& Speijer, R., 1997: Benthic foraminiferal Faunas and Trophic Regimes at the terminal cretaceousTethyan seafloor, V12, P354-371.

\section{PLATE}

1-: Guembelitria cretacea (Cushman). sample no 1Linawa

2-: Parvularugoglobigerina eugubina (Luterbacger and premoli Silva), umbilical view. Sample no 3Bady

3- Subbotina triloculinoides (Plummer), umbilical view . sample no 13Bady

4- Globanomalina compressa (Plummer), umbilical view . sample no 31Linawa

5- Praemurica uncinata (Bolli), umbilical view . sample no 15Bady

6- Morozovella angulata (White), umbilical view . sample no 42Linawa

7- Globanomalina pseudomenardii (Bolli), umbilical view . sample no 41Linawa

8- Morozovella velascoensis (Cushman), umbilical view . sample no 51Linawa 


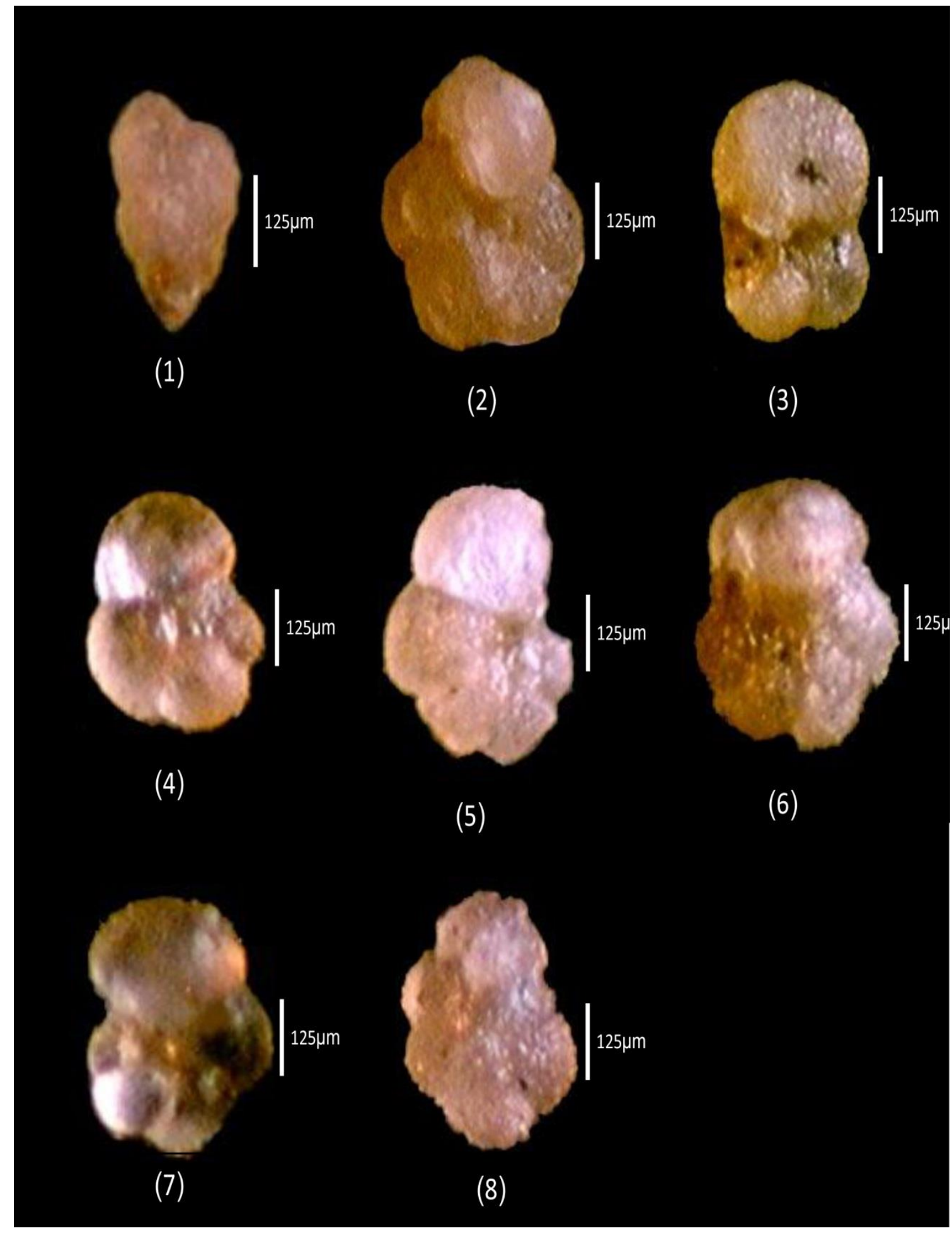

